\title{
FLIP $_{\mathrm{L}}$ Protects Neurons against In Vivo Ischemia and In Vitro Glucose Deprivation-Induced Cell Death
}

\author{
Era Taoufik, ${ }^{1}$ Samuel Valable, ${ }^{2 \star}$ Georg J. Müller, ${ }^{3 *}$ Michael L. Roberts, ${ }^{4 *}$ Didier Divoux, ${ }^{2}$ Antoine Tinel, ${ }^{5}$ \\ Anda Voulgari-Kokota, ${ }^{1}$ Vivian Tseveleki, ${ }^{1}$ Fiorella Altruda, ${ }^{6}$ Hans Lassmann, ${ }^{3}$ Edwige Petit, ${ }^{2}$ and Lesley Probert ${ }^{1}$ \\ ${ }^{1}$ Laboratory of Molecular Genetics, Hellenic Pasteur Institute, 11521 Athens, Greece, ${ }^{2}$ Universite de Caen, Unité Mixte de Recherche, Centre National de la \\ Recherche Scientifique 6185, 14074 Caen, France, ${ }^{3}$ Division of Neuroimmunology, Brain Research Institute, A-1090 Vienna, Austria, ${ }^{4}$ Regulon, 17455 \\ Athens, Greece, 5 Institute of Biochemistry, University of Lausanne, CH-1066 Epalinges, Switzerland, and ${ }^{\circ}$ Dipartimento di Genetica, Biologia e Biochimica, \\ Universita di Torino, 10126 Torino, Italy
}

Knowledge of the molecular mechanisms that underlie neuron death after stroke is important to allow the development of effective neuroprotective strategies. In this study, we investigated the contribution of death receptor signaling pathways to neuronal death after ischemia using in vitro and in vivo models of ischemic injury and transgenic mice that are deficient in tumor necrosis factor receptor I (TNFRI KO) or show neuron-specific overexpression of the long isoform of cellular Fas-associated death domain-like interleukin-1- $\beta$ converting enzyme-inhibitory protein $\left(\mathrm{FLIP}_{\mathrm{L}}\right)$. Caspase 8 was activated in brain lesions after permanent middle cerebral artery occlusion (pMCA0) and in cortical neurons subjected to glucose deprivation (GD) and was necessary for GD-induced neuron death. Thus, neurons treated with zIETD-FMK peptide or overexpressing a dominant-negative caspase 8 mutant were fully protected against GD-induced death. The presence of the neuroprotective TNFRI was necessary for selectively sustaining p50/p65NF- $\kappa \mathrm{B}$ activity and the expression of the p43 cleavage form of $\mathrm{FLIP}_{\mathrm{L}}$, FLIP(p43), an endogenous inhibitor of caspase 8, in pMCAO lesions and GD-treated neurons. Moreover, TNF pretreatment further upregulated p50/p65NF- $\kappa$ B activity and FLIP(p43) expression in neurons after GD. The knock-down of FLIP in wild-type (WT) neurons using a short hairpin RNA revealed that FLIP $_{\mathrm{L}}$ is essential for TNF/TNFRI-mediated neuroprotection after GD. Furthermore, the overexpression of FLIP $_{\mathrm{L}}$ was sufficient to rescue TNFRI KO neurons from GD-induced death and to enhance TNF neuroprotection in WT neurons, and neuron-specific expression of FLIP $_{\mathrm{L}}$ in transgenic mice significantly reduced lesion volume after pMCA0. Our results identify a novel role for the TNFRI-NF- $\kappa B-\mathrm{FLIP}_{\mathrm{L}}$ pathway in neuroprotection after ischemia and identify potential new targets for stroke therapy.

Key words: ischemia; neuroprotection; apoptosis; TNF receptor I; caspase 8; FLIP

\section{Introduction}

Brain ischemia, such as that occurring in stroke or chronic inflammatory diseases like multiple sclerosis, causes neuronal death through acute excitotoxicity and delayed death mechanisms (Dirnagl et al., 1999). To date, clinical trials for stroke treatment have focused mainly on targeting early excitotoxic events by blocking NMDA glutamate receptors and calcium channels, but the toxic side effects of the reagents used have prohibited their use in therapy (Lee et al., 2000). Promising results have come from preclinical studies using anti-apoptosis reagents that significantly limit expansion of the lesion beyond the ne-

\footnotetext{
Received 0ct. 4, 2006; revised April 17, 2007; accepted May 3, 2007.

This work was supported by the Hellenic General Secretariat of Research and Technology, PLATON Greece-France bilateral exchange collaboration grant and by the Sixth Framework Program of the European Union, NeuroproMiSe, LSHM-CT-2005-018637. We thank David Wallach and Eugene Varfolomeev for the murine C/S360 caspase 8 mutant, Jurg Tschopp for murine FLIP, CDNA, Kenneth Lundstrom for the PSFV(PD) vector, Horst Bluethmann for TNFRI KO mice, Sue Stevens for TN3 19-12 antibody, Ralph Budd and Nicolas Bidere for detailed bVAD pull-down protocols, and Voula Lambropoulou for help with primary neuron cultures.

*S.V., G.J.M., and M.L.R. contributed equally to this work.

Correspondence should be addressed to Lesley Probert, Laboratory of Molecular Genetics, Hellenic Pasteur Institute, 127 Vassilissis Sofias Avenue, 11521 Athens, Greece. E-mail: lesley_probert@hol.gr.

DOI:10.1523/JNEUROSCI.1091-07.2007

Copyright $\odot 2007$ Society for Neuroscience $\quad$ 0270-6474/07/276633-14\$15.00/0
}

crotic core. Overexpression of anti-apoptotic proteins such as Bcl-2 in neurons (Martinou et al., 1994), administration of neutralizing antibodies to Fas ligand (Martin-Villalba et al., 2001), and inhibition of the c-Jun N-terminal protein kinase (JNK) pathway with cell-penetrating peptides (Borsello et al., 2003) have conferred neuroprotection in experimental models of ischemia. Currently, targeting of apoptosis signaling pathways offers the most promising framework for the rational design of neuroprotective therapeutics for ischemia.

Death receptors (DRs) of the tumor necrosis factor receptor (TNFR) superfamily trigger apoptosis through caspase 8 . After ligand binding, caspase 8 is recruited to oligomerized DRs in a membrane-bound death-inducing signaling complex (DISC). Homodimers of caspase 8 autoprocess to form active caspase 8 , which cleaves caspase 3 to initiate apoptosis (Peter and Krammer, 2003) and can further amplify apoptosis signals by cleaving Bid to form jBid or tBid and thereby cross-talking to the JNK pathway and the mitochondria-mediated apoptosis pathway, respectively (Li et al., 1998; Deng et al., 2003). Unlike the other DRs, TNFRI mainly signals cell activation and proliferation and actively blocks apoptosis by upregulating nuclear factor $\kappa \mathrm{B}(\mathrm{NF}-\kappa \mathrm{B})$ activity and the expression of NF- $\kappa \mathrm{B}$-inducible anti-apoptotic pro- 
teins such as the cIAPs (cellular inhibitors of apoptosis), cellular Fas-associated death domain-like interleukin-1- $\beta$-converting enzyme-inhibitory protein (FLIP), TNFR-associated factor 1 (TRAF1), and TRAF2 (Karin and Lin, 2002). FLIP is a specific inhibitor of caspase 8-mediated apoptosis (Tschopp et al., 1998; Peter and Krammer, 2003). It is expressed as short (FLIP $\left.{ }_{S}\right)$ and long $\left(\mathrm{FLIP}_{\mathrm{L}}\right)$ isoforms, both of which inhibit procaspase 8 recruitment to the DISC and formation of active caspase 8 (Krueger

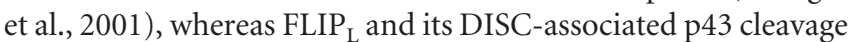
form FLIP(p43) can also induce NF- $\kappa$ B activity (Hu et al., 2000; Kataoka and Tschopp, 2004).

Genetic studies in mice have clearly demonstrated essential roles of TNFRI and NF- $\kappa \mathrm{B}$ in limiting infarct progression after ischemic injury and excitotoxicity in vivo (Bruce et al., 1996; Kaltschmidt et al., 1999), and biochemical studies in hippocampal neurons have revealed that excitotoxic stimuli trigger the TNFRI signaling cascade (Shinoda et al., 2003). However, it is unclear whether DR signaling pathways can be functional in neurons. In this study, we have used mice deficient in TNFRI and neuron-specific FLIP $\mathrm{L}_{\mathrm{L}}$ transgenic mice, combined with in vitro and in vivo models of ischemia, to show that caspase 8 is a critical mediator of glucose deprivation (GD)-induced neuron death. Furthermore, we identify a novel role for FLIP $_{\mathrm{L}}$ as a downstream mediator of TNF/TNFRI neuroprotection after GD and permanent middle cerebral artery occlusion (pMCAO).

\section{Materials and Methods}

Mice. Mice deficient in TNFRI (TNFRI KO) have been described previously (Rothe et al., 1993) and were backcrossed for 12 generations into the C57BL/6 background. For the generation of TgNFL-FLIP $\mathrm{L}_{\mathrm{L}}$ mice, the cDNA encoding for murine FLIP $_{\mathrm{L}}$ was cloned downstream of a $1.7 \mathrm{~kb} 5^{\prime}$ flanking sequence of the murine neurofilament gene (NFL) that confers neuron-specific expression of heterologous genes (Ivanov and Brown, 1992). Enhanced green fluorescent protein (eGFP) fused to the internal ribosome entry site (IRES) (Clontech, Basingstoke, UK) was cloned downstream of FLIP $\mathrm{I}_{\mathrm{L}}$ to provide an independent protein marker and facilitate screening of the transgenic founders and progeny. Six independent C57BL/ 6 transgenic lines were produced that expressed both FLIP

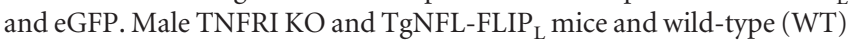
control littermates, weighing at least $30 \mathrm{~g}$ and aged between 3 and 4 months, were used for all ischemia procedures. GFP transgenic mice [TgN(act-EGFP)OsbC14-Y01-FM131] were donated by Masaru Okabe (Osaka University, Osaka, Japan). For neuron cultures, WT and TNFRI KO embryonic day 15 (E15) embryos were used. Animals were bred and maintained under specific pathogen-free conditions in the Experimental Animal Facility of the Hellenic Pasteur Institute. All animal procedures were approved by institutional review boards and national authorities and conformed to European Union guidelines.

Total RNA isolation and reverse transcription-PCR. Total RNA was extracted with TRIzol (Invitrogen, Paisley, UK) according to the manufacturer's instructions. DNase-treated (Promega, Southampton, UK) RNA was reverse transcribed with M-MLV Reverse Transcriptase (Promega) and random hexamers (Roche Diagnostics, Mannheim, Germany). The NFL-FLIP ${ }_{L}$-IRESeGFP transgene was amplified using the following primers on the GFP gene: forward, $5^{\prime}$-TGA ACC GCA TCG AGC TGA AGG C-3'; and reverse, $5^{\prime}$-TCC AGC AGG ACC ATG TGA TCG C-3'. Mouse $\beta$-actin was amplified as a loading control.

Primary neuronal cultures. Dissociated neocortical cell cultures were prepared from E15 WT and TNFRI KO mice as described previously (Nicole et al., 2001). Cells were plated onto poly-D-lysine/laminin (Sigma-Aldrich, Steinheim, Germany)-coated dishes at 400,000 cells/ $\mathrm{cm}^{2}$ for protein analyses and cell viability and at $200,000 \mathrm{cells} / \mathrm{cm}^{2}$ for immunohistochemical analysis. Cells were maintained in DMEM supplemented with $4.5 \mathrm{~g} / \mathrm{L}$ glucose (Sigma-Aldrich), 5\% FBS (Biochrom, Grundau, Germany), 5\% horse serum (Invitrogen) and 2 mM glutamine (Invitrogen). After $3 \mathrm{~d}$ in vitro (DIV3), $10 \mu \mathrm{M}$ ara-C (Sigma-Aldrich) was added to the medium to inhibit the proliferation of non-neuronal cells. All experiments were performed on DIV7, in cultures containing $<5 \%$ astrocytes, as determined by GFAP immunocytochemistry.

GD, oxygen-glucose deprivation, and experimental treatments. GD of neuron cultures was performed as described previously (Cheng et al., 1994) with minor modifications. Briefly, the maintenance medium was replaced by Locke's buffer containing the noncompetitive NMDA antagonist MK-801 (1 $\mu \mathrm{M}$; Sigma-Aldrich) to block secondary activation of NMDA receptors. Oxygen-glucose deprivation (OGD) was performed as described previously (Culmsee et al., 2003; Zhang et al., 2003). Briefly, glucose-free Locke's or Earle's balanced salt solutions were degassed by a mixture of $\mathrm{N}_{2} / \mathrm{CO}_{2}(95 \% / 5 \%)$ for $1 \mathrm{~h}$ before adding to neuronal cells. Cultures were then placed in an anaerobic chamber $\left(\mathrm{N}_{2} 95 \% / \mathrm{CO}_{2} 5 \%\right)$ and incubated for $3 \mathrm{~h}$. Control cultures were incubated in the same buffers with glucose in a normoxic incubator for the same period. After $3 \mathrm{~h}$, OGD was terminated by returning to normal culture conditions, and viability was assessed $24 \mathrm{~h}$ after reperfusion. Human recombinant TNF (R \& D Systems, Wiesbaden-Nordenstadt, Germany) was added to cultures $24 \mathrm{~h}$ before the onset of deprivation and was also included in the deprivation buffer. The caspase 8 inhibitor, zIETD-FMK (Merck Biosciences, Nottingham, UK) was added to cultures $30 \mathrm{~min}$ before deprivation and was included at the same concentrations in the deprivation medium.

Assessment of neuronal survival. Neuron survival was quantified by methods described previously (Cheng et al., 1994; Bruce et al., 1996). Trypan blue staining was used to assess neuronal survival at various time points after the onset of GD. Neurons were stained with $0.4 \%$ trypan blue dye solution (Sigma-Aldrich) and were considered viable if they excluded the dye and nonviable if they stained blue. Cells were counted in 10 different fields per well, in at least three separate cultures per treatment condition, by phase-contrast microscopy ( $40 \times$ objective). Experiments were repeated at least three times. Cell death was also visualized by staining the neuronal nuclei with the DNA-binding fluorochrome Hoechst 33258 (Sigma-Aldrich) according to standard protocols as described previously (Culmsee et al., 2003). Measurement of lactate dehydrogenase $(\mathrm{LDH})$ released from damaged neurons into the culture medium was performed as described previously (Koh and Choi, 1987), and culture medium of untreated neurons was used for normalization. Measurement of ATP levels was performed using the CellTiter-Glo Luminescent Cell Viability Assay (Promega) according to the manufacturer's instructions.

Semliki Forest virus vector production, infections, and assessment of neuronal survival. cDNAs encoding a dominant-negative form of caspase 8 (dnC8), FLIP ${ }_{\mathrm{L}}$, and IRESeGFP (Clontech) were cloned into a temperature-sensitive Semliki Forest virus (SFV) vector mutant, pSFV(PD) (Lundstrom et al., 2003). Linearized vector plasmid and pSFVHelper2 plasmid were in vitro transcribed using SP6 RNA polymerase (GE Healthcare, München, Germany). The resultant vector and helper RNA were coelectroporated into baby hamster kidney (BHK21) packaging cells. Cells were cultured at $31^{\circ} \mathrm{C}$ for $24 \mathrm{~h}$ in $25 \mathrm{~cm}^{2}$ flasks, and supernatants were collected. Chymotrypsin $(200 \mathrm{mg} / \mathrm{ml}$; Sigma-Aldrich) was added to activate viral particles. Inactivation of chymotrypsin was achieved by the addition of aprotinin $(0.25 \mathrm{mg} / \mathrm{ml}$; Sigma-Aldrich $)$, and the supernatants were spin-concentrated using a Vivaspin-20 centrifugation device (VivaScience, Hannover, Germany). For titration, near confluent BHK cells were infected with viral particles and incubated for $24 \mathrm{~h}$ at $37^{\circ} \mathrm{C}$. Titers were determined by counting the total number of GFP-positive cells in one well infected by $1 \mu l$ of viral suspension. All viral stocks were diluted in culture medium to achieve $70 \%$ infection of primary neurons. The effectiveness of infection was assessed by comparing the number of GFP-positive cells to the total cell number per well ( $40 \times$ objective). Cell viability was determined by counting the number of GFP cells that excluded trypan blue per field $(40 \times$ objective) in 10 different fields per well.

Lentivirus constructs and infection. Lentivirus expressing a specific short hairpin (shRNA) sequence for FLIP (Lenti-shFLIP) or a scrambled sequence [pLenti-shFLIP(scrambled)] was produced using the BLOCK-iT Lentiviral RNAi Expression System according to the manufacturer's instructions (Invitrogen). Titers were determined by infecting primary neurons with serial dilutions of concentrated lentivirus, and the 
dilution chosen for all infections (1:200) was tested by Western blot analysis for efficient knock-down of FLIP expression.

Permanent ischemia. All experiments were performed on adult male WT, TNFRI KO, and TgNFL-FLIP ${ }_{\mathrm{L}}$ mice under chloral hydrate anesthesia $(500 \mathrm{mg} / \mathrm{kg})$. Surgical protocols were approved by the local ethics committee and conformed to national legislation. Focal ischemia was induced by pMCAO as reported previously (Welsh et al., 1987; Bernaudin et al., 1999; Valable et al., 2005). During ischemia, physiological parameters remained in the normal range (body temperature, $37 \pm$ $0.3^{\circ} \mathrm{C} ; \mathrm{PaCO}_{2}, 40.9 \pm 4.2 \mathrm{mmHg} ; \mathrm{PaO}_{2}, 131.73 \pm 3.97 \mathrm{mmHg} ; \mathrm{pH}$ $7.08 \pm 0.08)$. At 3,6 , and $24 \mathrm{~h}$ after occlusion, mice were anesthetized, and brains were removed. Coronal brain sections $(20 \mu \mathrm{m})$ were cut on a cryostat and stained with thionin (Sigma-Aldrich). Total infarct volume $\left(\mathrm{mm}^{3}\right)$ was calculated after integration of infarcted areas determined on each section using the public domain ImageJ software with the distance $(400 \mu \mathrm{m})$ between each section level analyzed (Valable et al., 2005).

Western blot analysis. Total protein extracts from nonoccluded cortex (sham-operated animals) and the ischemic cortices (ipsilateral) of representative WT and TNFRI KO mice at various time points after ischemia were prepared by homogenizing the tissues in cold lysis buffer containing $50 \mathrm{~mm}$ Tris.HCl, pH 7.4, $250 \mathrm{~mm}$ sucrose, 1 mm EDTA, 1 mм EGTA, 10 $\mathrm{mm} \mathrm{NaF}, 1 \%$ Triton-X, and a mixture of inhibitors ( $1 \mathrm{~mm}$ benzamidine, $10 \mu \mathrm{g} / \mathrm{ml}$ aprotinin, $1 \mathrm{~mm}$ sodium orthovanadate, and $0.2 \mathrm{~mm}$ PMSF). Fifty micrograms of total protein extracts were boiled in a buffer containing 6\% SDS, 40\% glycerol, $125 \mathrm{~mm}$ DTT, and 3\% bromphenol blue, resolved on $10-12 \%$ polyacrylamide gels under denaturing conditions, and transferred onto nitrocellulose membranes (Schleicher \& Schuell, Dassel, Germany). Primary cortical neuron lysates were prepared in the same lysis buffer, and $30 \mu \mathrm{g}$ of total protein extracts was used for immunoblotting. Nuclear extracts from WT primary cortical neurons were prepared according to previously described methods (Culmsee et al., 2003) with some modifications. In brief, cells were harvested in cold PBS, and washed pellets were resuspended in $50 \mu \mathrm{l}$ of cold buffer A ( $10 \mathrm{mM}$ HEPES, pH 7.9, 10 mм KCl, 0.1 mм EDTA, pH 8.0, and 0.1 mм) EGTA supplemented with $0.1 \%$ Nonidet P-40, $1 \mathrm{~mm}$ dithiothreitol, $0.5 \mathrm{~mm}$ PMSF, $10 \mu \mathrm{g} / \mathrm{ml}$ aprotinin, $10 \mu \mathrm{g} / \mathrm{ml}$ leupeptin, and $1 \mathrm{~mm}$ sodium orthovanadate. Pellets were mixed briefly by vortexing and centrifuged at $12,000 \mathrm{rpm}$ at $4^{\circ} \mathrm{C}$. The supernatants contained cytoplasmic proteins, and the nuclear pellets were resuspended in $20 \mu$ l of cold buffer B ( $20 \mathrm{~mm}$ HEPES, pH 7.9, 400 mм NaCl, 1 mм EDTA, pH 8.0, and 1 mм EGTA) supplemented with the previously mentioned protein inhibitors. Extracts were then centrifuged, and supernatants corresponding to nuclear proteins were kept for additional analysis. Blots were probed with antibodies against phospho-IкBSer32 (1:1000; Cell Signaling Technology, Hitchin, UK), FLIP ${ }_{\mathrm{L} / \mathrm{S}}$ (1:1000; Santa Cruz Biotechnology, Santa Cruz, CA), caspase 8 (1:1000; Santa Cruz Biotechnology), caspase 3 (1:2000; Santa Cruz Biotechnology), GFP (1:3000; Millipore, Eschborn, Germany), mouse TNF (TN3 19-12; 1:500; UCB-Celltech, Slough, UK), mouse TNFRI (1:500; R \& D Systems), mouse TNFRII (1:500; clone HM102; HyCult, Uden, The Netherlands), phospho-JNK/stressactivated protein kinase (SAPK; 1:1000; Cell Signaling Technology), phospho-p38 (1:1000; Santa Cruz Biotechnology), phospho-mitogenactivated protein kinase (MAPK; 1:1000; Santa Cruz Biotechnology), p-Akt (1:1000; Cell Signaling Technology), Bcl-2 (1:1000; BD Biosciences, San Jose, CA), Bcl-X- ${ }_{-}$(1:1000; Cell Signaling Technology), Bad (1:1000; Cell Signaling Technology), and Bax (1:2000; Santa Cruz Biotechnology) at $4^{\circ} \mathrm{C}$ overnight. Specifically for the detection of caspase 8 active subunits, NuPage $4-12 \%$ Bis-Tris Gradient gels (Invitrogen) were loaded with $50 \mu \mathrm{g}$ of total protein and probed with the anti-caspase 8 antibody, clone 1 G12 (1:250; Alexis, Lausen, Switzerland). Secondary antibodies used were horseradish peroxidase-conjugated anti-rabbit or anti-mouse IgGs (1:2000 to 1:5000; Jackson ImmunoResearch, West Grove, PA). Antibody binding was detected using the ECL Plus detection system (GE Healthcare). To normalize for protein content, we stripped and reprobed membranes with anti- $\beta$-tubulin antibody $(1: 1000 ; \mathrm{BD}$ Biosciences). Densitometric analysis was performed using Image Quant 5.2 (Storm Scanner 600; Molecular Dynamics, Sunnyvale, CA), and relative band intensities have been determined.

Electrophoretic mobility shift assay. Electrophoretic mobility shift as- says (EMSAs) were performed using $50 \mu \mathrm{g}$ of total brain extracts from representative WT and TNFRI KO mice at different time points after pMCAO and $30 \mu \mathrm{g}$ of protein extracts from primary cortical neurons (protein extracts were prepared as described above). Proteins were incubated with an NF- $\kappa \mathrm{B}$ double-stranded oligonucleotide containing the consensus binding site of the $\kappa \mathrm{B}$ enhancer (AGT TGA GGG GAC TTT CCC AGG C) that was end-labeled with $\gamma \mathrm{ATP}^{32} \mathrm{P}$, using T4 kinase (Promega) in the following buffer: $10 \mu \mathrm{g} / \mathrm{ml} \mathrm{BSA}, 20 \mathrm{~mm}$ HEPES, $\mathrm{pH} 7.5,1$ mu EDTA, 1\% Nonidet P-40, 5\% glycerol, 5 mm DTT, and $0.15 \mathrm{mg} / \mathrm{ml}$ poly dI-dC. DNA-protein complexes were resolved on $4 \%$ native polyacrylamide gels. To determine specificity of the complexes, competition experiments were performed by incubating selected protein extracts with an excess either of unlabeled consensus or of a mutated consensus binding sequence (AGT TGA CCA TGG TAT CCC AGG C) (Schneider et al., 1999). For supershift experiments, extracts were preincubated for $12 \mathrm{~h}$ at $4^{\circ} \mathrm{C}$ with either an anti-p65 or a p50 antibody (Santa Cruz Biotechnology).

Immunocytochemistry. Immunocytochemistry was performed on paraffin brain sections as described previously (Rossler et al., 1992). Primary antibodies were as follows: rabbit anti-NF- $\kappa$ B p65 (1:100; Cell Signaling Technology), mouse anti-NeuN (1:100; Millipore), anti-Mac3 (1:100; BD Biosciences), and rat anti-human CD3 (1:400; Serotec, Oxford, UK). Antibody binding was visualized by biotinylated secondary antibody followed by horseradish peroxidase-labeled avidin-biotin complex and 3,3-diaminobenzidine tetrahydrochloride. To assess nuclear morphology, all sections were strongly counterstained with hematoxylin. For double-immunofluorescence staining, NeuN and NF- $\kappa$ B p 65 were incubated together and visualized by anti-mouse Cy3-labeled (red) antibody and a secondary biotinylated anti-rabbit antibody followed by an Alexa 488-labeled avidin (green) antibody (Jackson ImmunoResearch), respectively. FLIP localization in primary cortical neurons was detected on $4 \%$ paraformaldehyde fixed neurons with rabbit anti-FLIP ${ }_{L / S}$ (1:500; Santa Cruz Biotechnology) and anti-rabbit Alexa 568 (1:2000; Invitrogen). Preabsorption of anti-FLIP ${ }_{\mathrm{L} / \mathrm{S}}$ antibody at the optimal staining dilution (1:500) was achieved by preincubation with increasing concentrations of recombinant human FLIP (rhFLIP) protein (R \& D Systems) at $4^{\circ} \mathrm{C}$ overnight.

Caspase 8/caspase 3 activity assays. Protein fractions were isolated from primary cortical neurons and subjected to GD, in the presence of zIETDFMK $(50 \mu \mathrm{M})$ and after pSFV-IRESeGFP or pSFV-dnC8-IRESeGFP infections. Caspase- 3 activity was measured by mixing $10 \mu \mathrm{l}$ of cell lysate (30-40 $\mu$ g of protein) with $100 \mu \mathrm{l}$ of reaction buffer [10 mM Tris-HCl, pH 7.4, 0.1\% CHAPS (3-[(3-cholamidopropyl)dimethylammonio]-1propanesulfonate), $2 \mathrm{~mm} \mathrm{MgCl}_{2}, 1 \mathrm{~mm}$ dithiothreitol, $5 \mathrm{~mm}$ EGTA, and $150 \mathrm{~mm} \mathrm{NaCl}$ ] containing a fluorogenic caspase-3 substrate (Ac-DEVDAMC; $50 \mu \mathrm{M}$; Apotech, Epalinges, Switzerland) or caspase-8 (Ac-IETDAMC; Apotech). The mixture was incubated for $60 \mathrm{~min}$ in an enzymelinked immunosorbent assay titer plate, and fluorescence was measured in a Fluoroskan enzyme-linked immunosorbent assay reader (excitation, $355 \mathrm{~nm}$; emission, $460 \mathrm{~nm}$ ).

Biotin-VAD-FMK caspase precipitation assay. Activated caspase 8 detection was performed using the bVAD-FMK precipitation assay according to previously described protocols with some modifications (Misra et al., 2005; Tu et al., 2006). Neurons were treated with $30 \mu \mathrm{M} \mathrm{z}$-IETD-FMK (Merck Biosciences) or DMSO for $30 \mathrm{~min}$. To assess the inhibition of caspase 8 attributable to the $\mathrm{dnC} 8$, neurons were infected with the pSFVdnC8-IRESeGFP or the control vector pSFV-IRESeGFP for $12 \mathrm{~h}$. Cells were then incubated with $50 \mu \mathrm{m}$ bVAD-FMK (Enzyme Systems Products, Livermore, CA) or DMSO control for $2 \mathrm{~h}$ at $37^{\circ} \mathrm{C}$ before GD. After $6 \mathrm{~h}$ of GD, cells were lysed in buffer containing $20 \mathrm{~mm}$ Tris. $\mathrm{HCl}, \mathrm{pH}$ 7.4, $150 \mathrm{~mm} \mathrm{NaCl}, 0.2 \% \mathrm{NP}-40,2 \mathrm{~mm}$ orthovanadate, and 10\% glycerol, supplemented with complete protease inhibitor (Roche Diagnostics) and $10 \mu \mathrm{m}$ bVAD-FMK. A total of $600 \mu \mathrm{g}$ was precleared with protein $\mathrm{A} / \mathrm{G}$ (Santa Cruz Biotechnology) for $2 \mathrm{~h}$ at $4^{\circ} \mathrm{C}$. Supernatants were then incubated overnight with streptavidin-Sepharose beads (Zymed Laboratories, South San Francisco, CA) at $4^{\circ} \mathrm{C}$ overnight. Beads were washed five times with lysis buffer without protease inhibitors and boiled in loading buffer. Beads were removed by centrifugation, and immunoblot analysis for active caspase 8 detection was performed on the supernatants.

Statistics. All statistical analyses were performed with SigmaStat 2.0 for 
Windows (SPSS, Chicago, IL). All data are given as mean \pm SEM. To determine significant difference between infarct volumes of WT and TNFRI KO mice at different time points after pMCAO (see Fig. 5A), one-way ANOVA on ranks followed by Dunn's test was performed for pairwise comparisons because the group sizes were unequal at each time point, and the experiments were performed independently (Bruce et al., 1996). For WT and TgNFLFLIP $_{\mathrm{L}}$ mice (see Fig. 9F), Student's $t$ test was used. For comparisons of neuron viability, $\mathrm{LDH}$ release, and ATP levels, for which the multiple groups are concurrently analyzed, one-way ANOVA with Bonferroni correction was performed (Cheng et al., 1994). Similarly, to determine significant decreases in caspase 8 and caspase 3 activity in neurons, the mean values of all groups were analyzed by one-way ANOVA followed by Bonferroni $t$ test. Mac 3-positive cells (see Fig. 5C) and p65-positive nuclei (see Fig. $6 E$ ) in $24 \mathrm{~h}$ pMCAO lesions were analyzed using the Mann-Whitney rank sum test. For all Western blot analyses, a semiquantitative measurement of the band intensity was performed with Image Quant 5.2 (Molecular Dynamics Storm Scanner 600) and expressed as pixel intensity per unit area. For Western blots, all densitometry values were normalized to their respective tubulin values. Protein levels were compared using one-way ANOVA followed by Bonferroni $t$ test for pairwise comparisons. For EMSA analyses, ANOVA followed by rank sum test was used. $p$ values $<0.05$ were considered statistically significant.

\section{Results}

Caspase 8 is activated in pMCAO

lesions and in cortical neurons after GD To investigate the function of DR signaling in neurons after ischemic injury, we first analyzed the expression and activity of caspase 8 in pMCAO lesions and in highly enriched primary neuron cultures subjected to established in vitro models of ischemic injury. Procaspase $8(55 \mathrm{kDa})$ was constitutively expressed in the cerebral cortex of WT and TNFRI KO mice, and levels were significantly elevated in the TNFRI KO at 3 and $6 \mathrm{~h}$ after pMCAO (Fig. $1 A)$. The activated $43 / 41 \mathrm{kDa}$ form of caspase 8 [caspase $8(\mathrm{p} 43)$ ], which is formed within the DISC (Peter and Krammer, 2003), and the p18 subunit of active caspase 8 [caspase $8(\mathrm{p} 18)$ ], were elevated in both strains of mice $3 \mathrm{~h}$ and 3 and $6 \mathrm{~h}$, respectively, after pMCAO (Fig. $1 A$ ).

To investigate the contribution of neurons to caspase 8 and caspase 3 expression, we isolated cortical neurons from WT and TNFRI KO mice and subjected them to GD or OGD. WT and TNFRI KO neurons constitutively expressed high levels of procaspase 8 (Fig. $1 B$ ). Shortly after GD (15 and $90 \mathrm{~min}$ ), the expression of caspase $8(\mathrm{p} 43)$ and caspase $8(\mathrm{p} 18)$ were also detected (Fig. $1 B)$. Activation of caspase 8 after GD was further confirmed by

A

D WT TNFRI KO
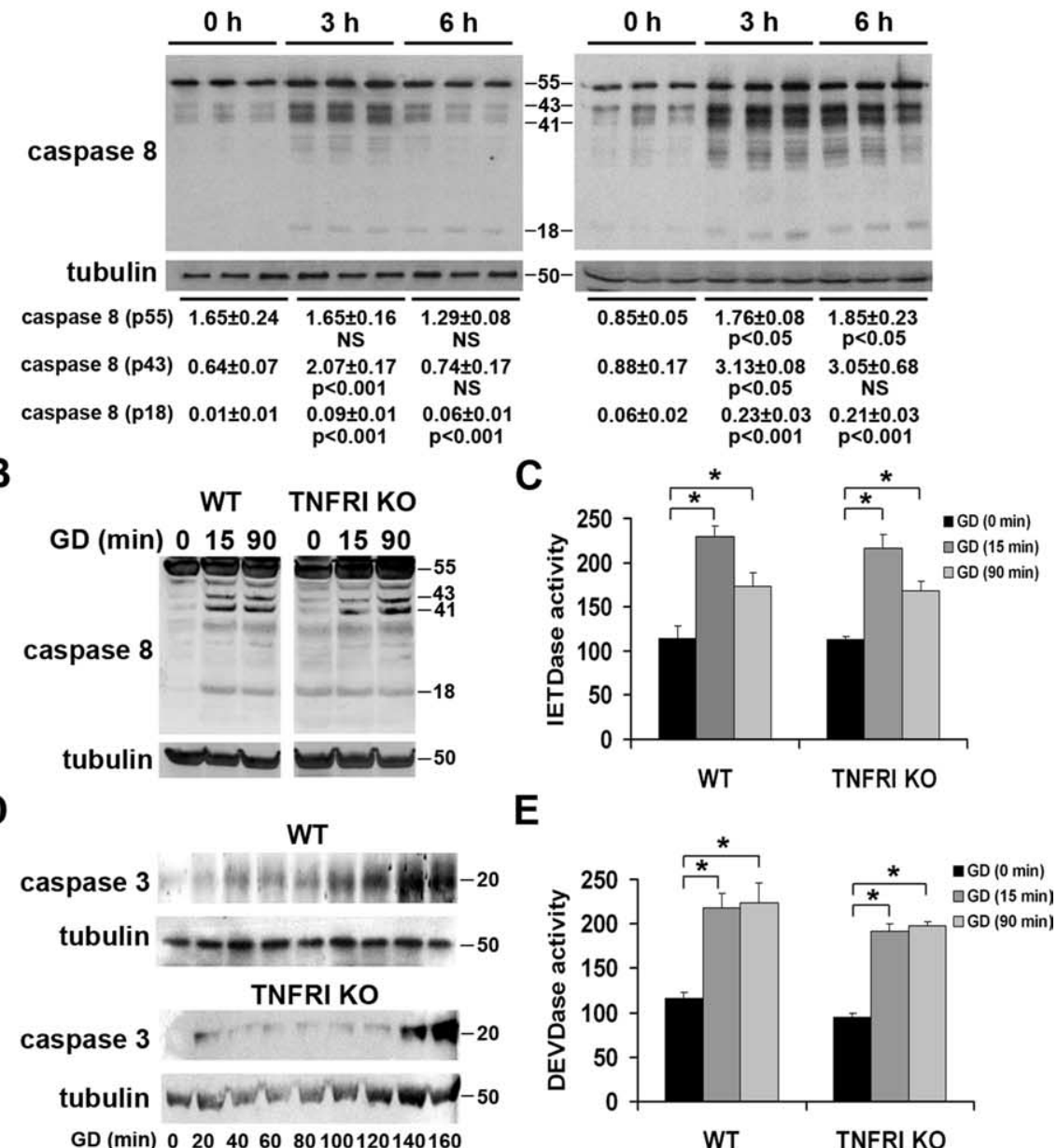

E

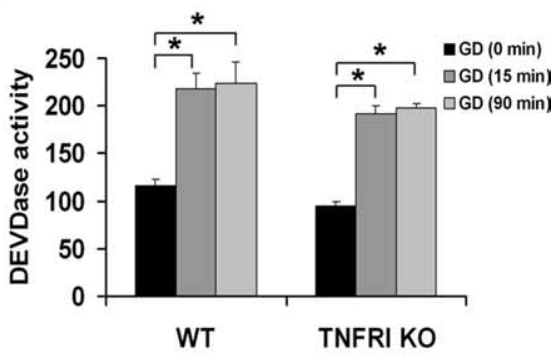

G
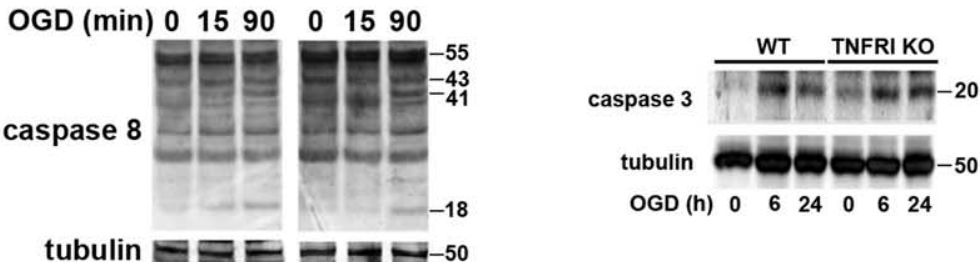

Figure 1. Caspase 8 activation in pMCAO lesions and GD-treated neurons. $A$, Caspase 8 expression was assessed in WT $(n=3)$ and TNFRI KO ( $n=3$ ) cortical lysates from nonoccluded animals and in ischemic cortices at $3 \mathrm{~h}$ (WT, $n=3$; TNFRI KO, $n=3$ ) and $6 \mathrm{~h}$ (WT, $n=3$; TNFRI KO, $n=3$ ) after occlusion. Values represent the mean densitometry \pm SEM and significance. NS, Nonsignificant. $\boldsymbol{B}$, Caspase 8 expression was assessed at 15 and 90 min after GD induction in WT and TNFRI KO neurons. C, Caspase 8 (IETDase) activity of WT and TNFRI KO neurons 15 and $90 \mathrm{~min}$ after GD. Activity counts represent the mean value from duplicate samples \pm SEM from one representative experiment of two performed. ${ }^{*} p<0.001$ for comparison of IETDase activity before and after GD. D, Caspase 3(p20) expression in WT and TNFRI KO neurons at 20 min intervals after GD. E, Caspase 3 (DEVDase) activity of WT and TNFRI KO neurons after GD. Activity counts represent the mean value from duplicate samples \pm SEM from one representative experiment of two performed. ${ }^{*} p<0.001$ for comparison of DEVDase activity before and after GD. Interestingly, as for caspase 8, detectable levels of caspase 3 activity were found in neurons before deprivation, and the functional significance of this is not known. $F$, Caspase 8 expression in WT and TNFRI KO neurons at 15 and $90 \mathrm{~h}$ after reperfusion following OGD. G, Caspase 3 (p20) expression in WT and TNFRI KO neurons at 6 and $24 \mathrm{~h}$ after reperfusion following $0 G D$. For all in vitro experiments, results are representative of three independent experiments.

measurement of the proteolytic activity of caspase 8 in WT and TNFRI KO neurons at the same time points (Fig. 1C).

The active form of the downstream apoptosis effector caspase 3 [caspase 3(p20)] was also detectable in WT and TNFRI KO neurons $20 \mathrm{~min}$ after GD and steadily accumulated up to the last time point studied (Fig. $1 D$ ). Caspase 3 proteolytic activity was 
A

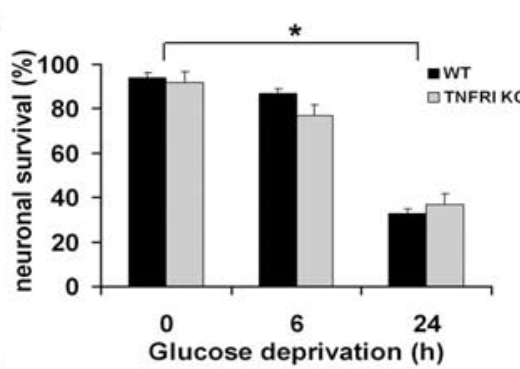

C

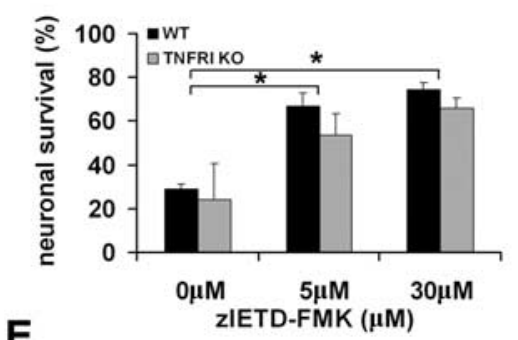

E

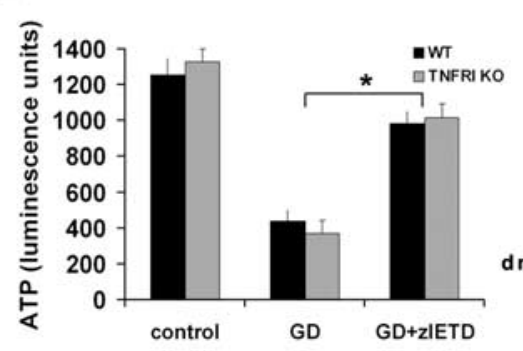

G

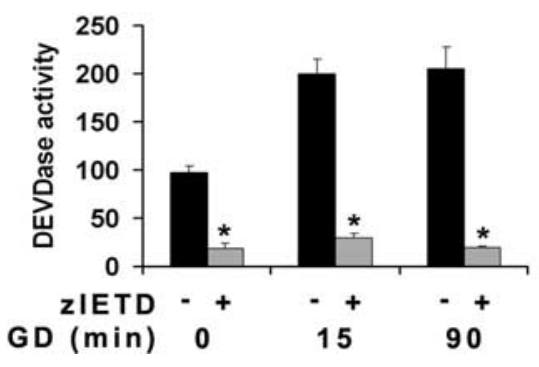

Figure 2. Caspase 8 mediates GD-induced neuron death independently of TNFRI. $\boldsymbol{A}$, Survival of WT and TNFRI KO neurons after $G D$. Values represent the mean survival $\pm S E M$ of triplicates from two independent experiments. ${ }^{*} p<0.001$ for comparison of WT and TNFRI KO neuronal survival before and $24 \mathrm{~h}$ after GD. B, Morphology of WT neurons stained with Hoechst 33258 , before (left) and $24 \mathrm{~h}$ after (right) GD (40× objective). C, Viability of WT and TNFRI KO neurons treated with zIETD-FMK was assessed $24 \mathrm{~h}$ after GD. Survival values represent the mean \pm SEM of triplicates from two independent experiments. ${ }^{*} p<0.001$ for comparison of untreated and zIETD-FMK-treated WT and TNFRI KO neurons. D, Neuronal damage quantified by measuring LDH release into the culture medium of WT and TNFRI KO neurons treated with zIETD-FMK $24 \mathrm{~h}$ after GD. ${ }^{*} p<0.01$ for comparison of untreated and zIETD-FMK-treated WT and TNFRI KO neurons. Results shown represent the mean LDH release \pm SEM of triplicate samples after normalization to the control (untreated neurons) from two independent experiments. $E$, ATP levels of WT and TNFRI KO neurons treated with zIETD-FMK $4 \mathrm{~h}$ after GD. ${ }^{*} p<0.01$ for comparison of untreated and zIETD-FMK-treated WT and TNFRI KO neurons. Results shown represent the mean ATP levels \pm SEM of triplicate samples from two independent experiments. $F$, Immunoblot for caspase 8 performed on nonprecipitated whole-cell lysates (WCL; lanes 1,2) and bVAD precipitates (lanes 3,4) from WT neurons before and $6 \mathrm{~h}$ after GD. bVAD precipitates from zIETD-FMK-pretreated neurons (lanes 5) and from pSFV-dnC8-IRESGFP-infected neurons (lanes 6,7$)$ were also used to assess caspase 8 inhibition. Results are representative of two independent bVAD experiments. pptn, Precipitation. G, Caspase 3 (DEVDase) activity of WT neurons treated with zIETD-FMK. Activity counts represent the mean value from duplicate samples \pm SEM from one representative experiment of two performed. ${ }^{*} p<0.001$ for comparisons of DEVDase activity between untreated and treated WT neurons.

also increased after GD (Fig. $1 E$ ). In a manner similar to GD, OGD activated the caspase 8 - caspase 3 pathway in WT and TNFRI KO neurons, as shown by the appearance of caspase $8(\mathrm{p} 43)$, caspase $8(\mathrm{p} 18)$, and caspase $3(\mathrm{p} 20)$ subunits after reoxygenation (Fig. $1 F, G)$.

\section{Caspase 8 mediates neuron death} after GD

To determine the contribution of caspase 8 to neuron death after GD and OGD, we pretreated WT and TNFRI KO neurons with zIETD-FMK, subjected them to GD or OGD, and measured neuron viability after $24 \mathrm{~h}$. GD resulted in $73 \pm 1.9 \%$ death of WT and $71.4 \pm 2.3 \%$ death of TNFRI KO neurons (Fig. 2A). Hoechst staining showed that the majority of deprived neurons developed pyknotic nuclei exposing an intense fluorescence staining that are typical of apoptotic cells by $24 \mathrm{~h}$, compared with nondeprived cells, which maintained their smooth and roundshaped nuclei with low fluorescence exposure (Fig. 2 B). zIETD-FMK potently inhibited death in both WT and TNFRI KO neurons in a dose-dependent manner as measured by trypan blue exclusion (Fig. $2 C)$. Measurements of $\mathrm{LDH}$ release and ATP levels confirmed that zIETD-FMK significantly protected neurons against GD damage (Fig. 2D,E). To further measure the effectiveness of inhibition of active caspase 8 formation by zIETD-FMK after GD, we performed a caspase precipitation assay using the biotinylated form of VAD-FMK (bVAD-FMK) with immobilized streptavidin. The bVAD-FMK pull-down has been used to isolate active caspases, including caspase 8 , from lysates and other in vitro preparations (Misra et al., 2005; Tu et al., 2006), and it has been recently demonstrated that bVAD-FMK, if present in a cell during apoptosis induction, binds to the initiator caspases that are activated and halts the process at this point (Tu et al., 2006). Using this approach, many groups have shown that caspase 8 is active in its full-length form (Dohrman et al., 2005; Misra et al., 2005; Tu et al., 2006). Similarly, based on this assay, we were able to show that although neurons express constitutively high levels of fulllength caspase 8 (Fig. $2 F$, lane 1 ), it does not bind bVAD-FMK and is therefore inactive (Fig. $2 F$, lane 3). After GD, procaspase 8 binds bVAD-FMK in neurons, showing its activation, and this was inhibited by the caspase inhibitor zIETD-FMK (Fig. 2F, lanes 4-5). This correlated with a significant decrease of caspase 3 enzymatic activity in the presence of zIETD-FMK after GD (Fig. 2G).

OGD resulted in $45 \pm 15 \%$ death of WT and $43 \pm 18 \%$ of TNFRI KO neurons (Fig. 3A), and Hoechst staining confirmed that a proportion of neurons undergo apoptosis $24 \mathrm{~h}$ after reperfusion (Fig. $3 B$ ). However, unlike GD conditions, zIETD-FMK was unable to inhibit OGD-induced cell death at any of the concentrations tested (Fig. 3C). Measurements of LDH release and ATP levels con- 
firmed that zIETD-FMK did not protect neurons against OGD damage (Fig. $3 D, E)$. In addition, Hoechst staining showed that zIETD-FMK was unable to protect neuron morphology (data not shown).

Collectively, these results demonstrate that although caspase 8 is activated in both GD- and OGD-treated neurons, it is a critical mediator for death only in the GD model, indicating that alternative death mechanisms are important in the OGD model. Also, the finding that GD-induced neuron death and caspase 8 activation occur independently of the presence of TNFRI indicates that they are triggered by other neuronal DRs or intrinsic stress signals.

To confirm the role of caspase 8 in mediating GD-induced neuron apoptosis, we infected WT and TNFRI KO neurons with a Semliki Forest virus (Lundstrom et al., 2003) engineered to express a dominant-negative caspase 8 (pSFV-dnC8IRESeGFP) carrying an inactivating mutation in the protease domain of murine caspase 8 (C360S). As control, we used the pSFV virus expressing the GFP protein alone (pSFV-IRESeGFP). pSFV-dnC8IRESeGFP infection of WT neurons resulted in a sevenfold increase in the level of caspase 8 protein by $12 \mathrm{~h}$ after infection compared with pSFV-IRESeGFP infection (Fig. 4A). Neurons from both strains were infected with pSFV-dnC8-IRESeGFP or pSFV-IRESeGFP and subjected to GD. Neuron viability at $24 \mathrm{~h}$ after GD was greatly enhanced by overexpression of the dnC8 (WT, $73 \pm 5 \%$; TNFRI KO, $77 \pm$ $3 \%)$ compared with overexpression of eGFP alone (WT, $32 \pm 10 \%$; TNFRI KO, $38 \pm 10 \%)$ as measured by trypan blue exclusion (Fig. $4 B$ ) and was comparable with that obtained with zIETD-FMK (Fig. 2E). LDH release from pSFV-dnC8-IRESeGFP-infected neurons was significantly decreased compared with cells infected with the control virus $24 \mathrm{~h}$ after GD (Fig. 4C). WT neurons that were infected with pSFV-dnC8-IRESeGFP maintained their normal appearance, with smooth soma and outgrown neurites (Fig. $4 D$, right), in contrast to pSFVIRESeGFP-infected neurons that exhibited swelling and condensation of the soma and neurite fragmentation (Fig. $4 D$, left). To confirm that pSFV-dnC8-IRESeGFP acts by inhibiting caspase $8 /$ caspase 3 -mediated neuron death, we measured activation of caspase 8 by Western blot and bVAD-FMK pull-down assay, and caspase 3 activity using the DEVDase activity assay. pSFV-dnC8IRESeGFP infection of WT and TNFRI KO neurons strongly inhibited caspase 8 activation, as shown by prevention of caspase 8(p18) formation (Fig. $4 E$ ) and by the large depletion of bVADFMK-bound procaspase 8 (Fig. $2 F$, lanes 5-7). In addition, caspase 3 activity was effectively inhibited in the pSFV-dnC8IRESeGFP-infected neurons after GD compared with control vector-infected cells (Fig. $4 F$ ).
B

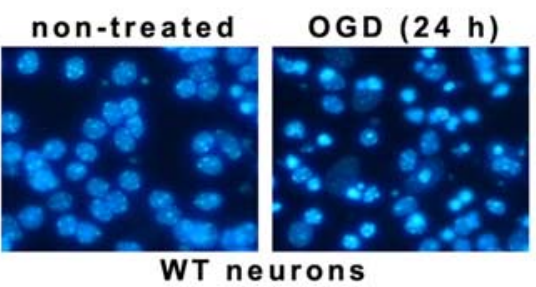

024

24

D

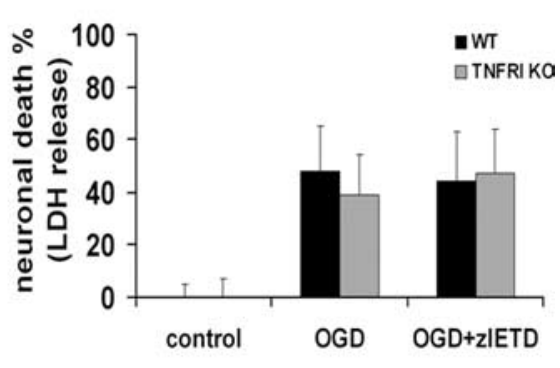

- WT

口TNFRI KO

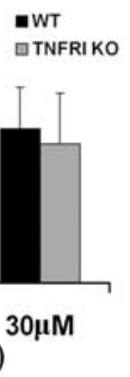

$\stackrel{5 \mu \mathrm{M}}{\text { zIETD-FMK }(\mu \mathrm{M})}$ 


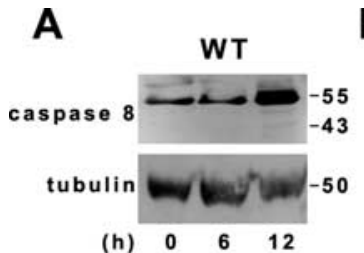

C
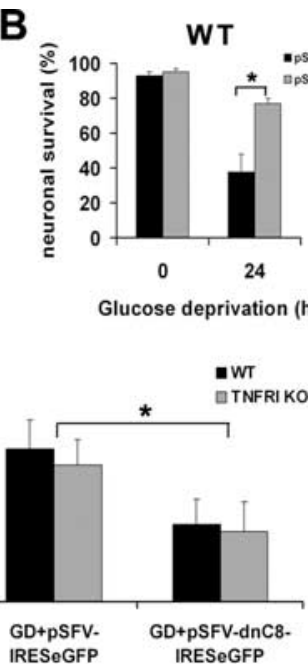

D

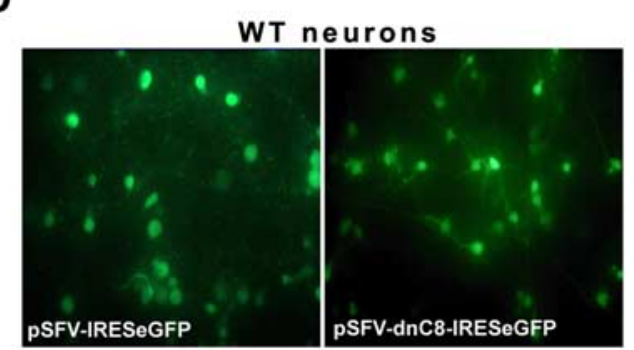

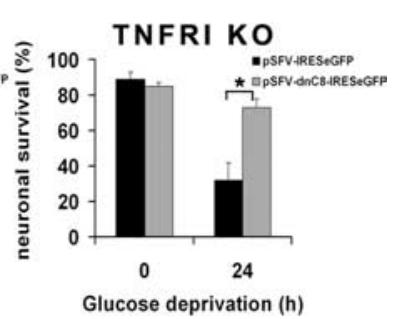

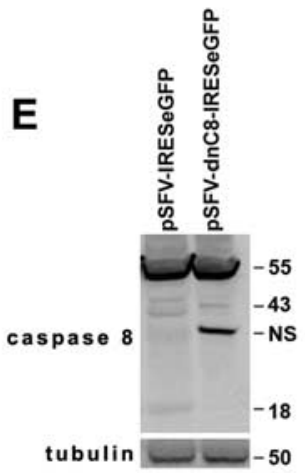

$\mathbf{F}$

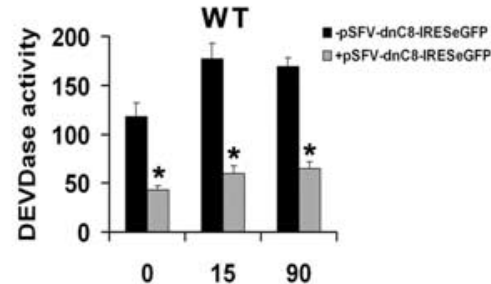

Glucose deprivation (min)

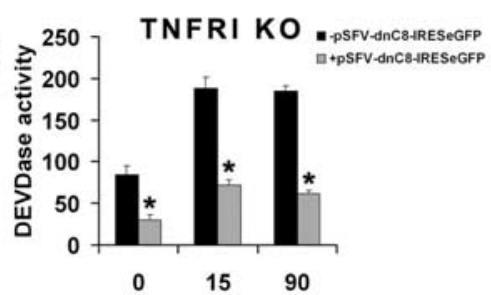

Glucose deprivation ( $\mathrm{min})$

Figure 4. Overexpression of a dominant-negative mutant of caspase 8 improves neuronal survival after GD. $\boldsymbol{A}$, Procaspase 8 expression in WT neurons after infection with a pSFV-dnC8-IRESeGFP virus for 6 and $24 \mathrm{~h}$ (representative Western blot from 4 independent experiments). $\boldsymbol{B}$, Survival of pSFV-IRESeGFP- or pSFV-dnC8-IRESeGFP-infected WT and TNFRI KO neurons after GD. Values represent the mean survival \pm SEM of triplicates from two independent experiments. ${ }^{*} p<0.01$ for comparison of neuronal survival $24 \mathrm{~h}$ after GD of pSFV-IRESeGFP- or pSFV-dnC8-IRESeGFP-infected WT (left graph) or TNFRI KO (right graph) neurons. $C$, Neuronal damage quantified by measuring LDH release into the culture medium of WT and TNFRI KO neurons infected with pSFV-IRESeGFP or pSFV-dnC8-IRESeGFP, 24 h after GD. ${ }^{*} p<0.05$ for comparison of pSFV-IRESeGFP- or pSFV-dnC8IRESeGFP-infected WT and TNFRI KO neurons. Results shown represent the mean LDH release \pm SEM of triplicate samples from three independent experiments. D, Fluorescent microscopy (40× objective) of WT neurons infected with pSFV-IRESeGFP virus (left) and with pSFV-dnC8-IRESeGFP virus (right) and subjected to GD for $24 \mathrm{~h}$. $\boldsymbol{E}$, Caspase 8 expression in pSFV-IRESeGFP or pSFV-dnC8-IRESeGFP WT neurons 15 min after GD. A representative Western blot of two performed is shown. NS, Nonspecific band of $\sim 32 \mathrm{kDa}$. $\boldsymbol{F}$, Caspase 3 (DEVDase) activity of pSFV-IRESeGFP- or pSFV-dnC8-IRESeGFP-infected WT and TNFRI KO neurons after GD. Activity counts represent the mean value from triplicate samples \pm SEM from one representative experiment of two performed. ${ }^{*} p<0.05$ for comparison of DEVDase activity of pSFV-IRESeGFP- or pSFV-dnC8-IRESeGFP-infected WT (left graph) or TNFRI KO (right graph) neurons before and after GD.

To investigate the physiological significance of the observed effects, we looked at the expression of TNF and TNFRI in WT and TNFRI KO cerebral cortex. Constitutive expression of transmembrane TNF $(26 \mathrm{kDa})$ was detectable in both WT and TNFRI KO cortex. Transmembrane TNF was strongly upregulated in WT but not TNFRI KO mice at $3 \mathrm{~h}$ after occlusion (Fig. $5 D$ ). TNFRI was constitutively expressed in WT but not TNFRI $\mathrm{KO}$ brain and upregulated in WT lesions at $3 \mathrm{~h}$ after pMCAO (Fig. 5E).
To investigate whether TNFRI exerts direct neuroprotective effects in neurons and whether triggering by its ligand can enhance this effect, we pretreated WT and TNFRI KO neurons with increasing concentrations of human TNF, which selectively activates the murine TNFRI (Lewis et al., 1991) and subjected them to GD. TNF significantly enhanced WT but not TNFRI KO neuron survival (Fig. $5 F$ ), decreased LDH release (Fig. 5G), and maintained ATP levels (Fig. 5H) in WT neurons at $24 \mathrm{~h}$ after $\mathrm{GD}$ in a dose-dependent manner. Immunoblot analysis confirmed that WT neurons express TNFRI, whereas WT and TNFRI KO neurons express comparable levels of TNFRII (Fig. 5I). We looked at the effect of TNF pretreatment on GD-induced caspase 3 activation. TNF pretreatment enhanced early caspase 3(p20) formation in WT neurons, but levels returned to baseline by $100 \mathrm{~min}$ after GD (Fig. 5J). These data show that TNF signals neuroprotection and suppression of active caspase 3(p20) generation directly through the neuronal TNFRI after GD. In contrast, TNF pretreatment did not improve neuron survival after OGD as shown by LDH release and ATP levels 24 and $4 \mathrm{~h}$, respectively, after reperfusion (Fig. $5 K, L$ ).

\section{TNFRI is necessary for NF- $\kappa B$ activation in pMCAO lesions and GD-treated neurons}

TNF is a strong inducer of neuronal $\kappa \mathrm{B}$ dependent transcription, and its neuroprotective effects have been correlated with NF- $\kappa \mathrm{B}$ activation in neurons (Barger et al., 1995). To determine whether TNFRI is necessary for NF- $\kappa$ B activation after pMCAO, we assessed the levels of NF- $\kappa \mathrm{B}$ activity in WT and TNFRI KO cortex by EMSA. Two bands of constitutive NF- $\kappa$ B activity were detectable that corresponded to $\mathrm{p} 50 / \mathrm{p} 65$ heterodimers (top band) and p50/p50 homodimers (bottom band), as demonstrated by supershift analysis of the complexes with p50 and p65 antibodies and competition experiments with a cold probe (Fig. 6A). Specificity of the two bands was further demonstrated by the absence of competition by a mutant oligo (supplemental Fig. 1, available at www. jneurosci.org as supplemental material). NF- $\kappa \mathrm{B}$ activity was detectable in WT lesions 3 and $6 \mathrm{~h}$ after pMCAO (Fig. 6A). In contrast, DNA-binding activity was significantly diminished in TNFRI KO lesions after pMCAO (Fig. 6A). Accordingly, levels of phosphorylated $\mathrm{I} \kappa \mathrm{B}(\mathrm{p}-\mathrm{I} \kappa \mathrm{B})$ were significantly increased in $\mathrm{WT}$, but not TNFRI KO, lesions $6 \mathrm{~h}$ after pMCAO (Fig. 6B). Immunocytochemistry of ischemic lesions using an NF- $\kappa \mathrm{B}$ p 65 -specific antibody showed the presence of numerous p65-positive cells in $\mathrm{WT}$ lesions $24 \mathrm{~h}$ after pMCAO, the majority showing neuronal 


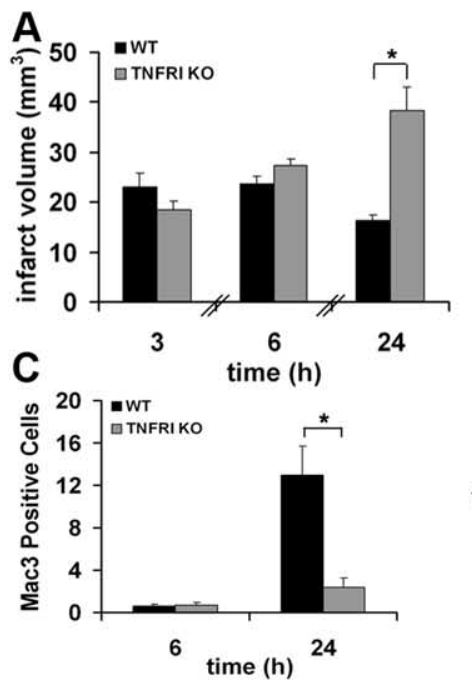

B
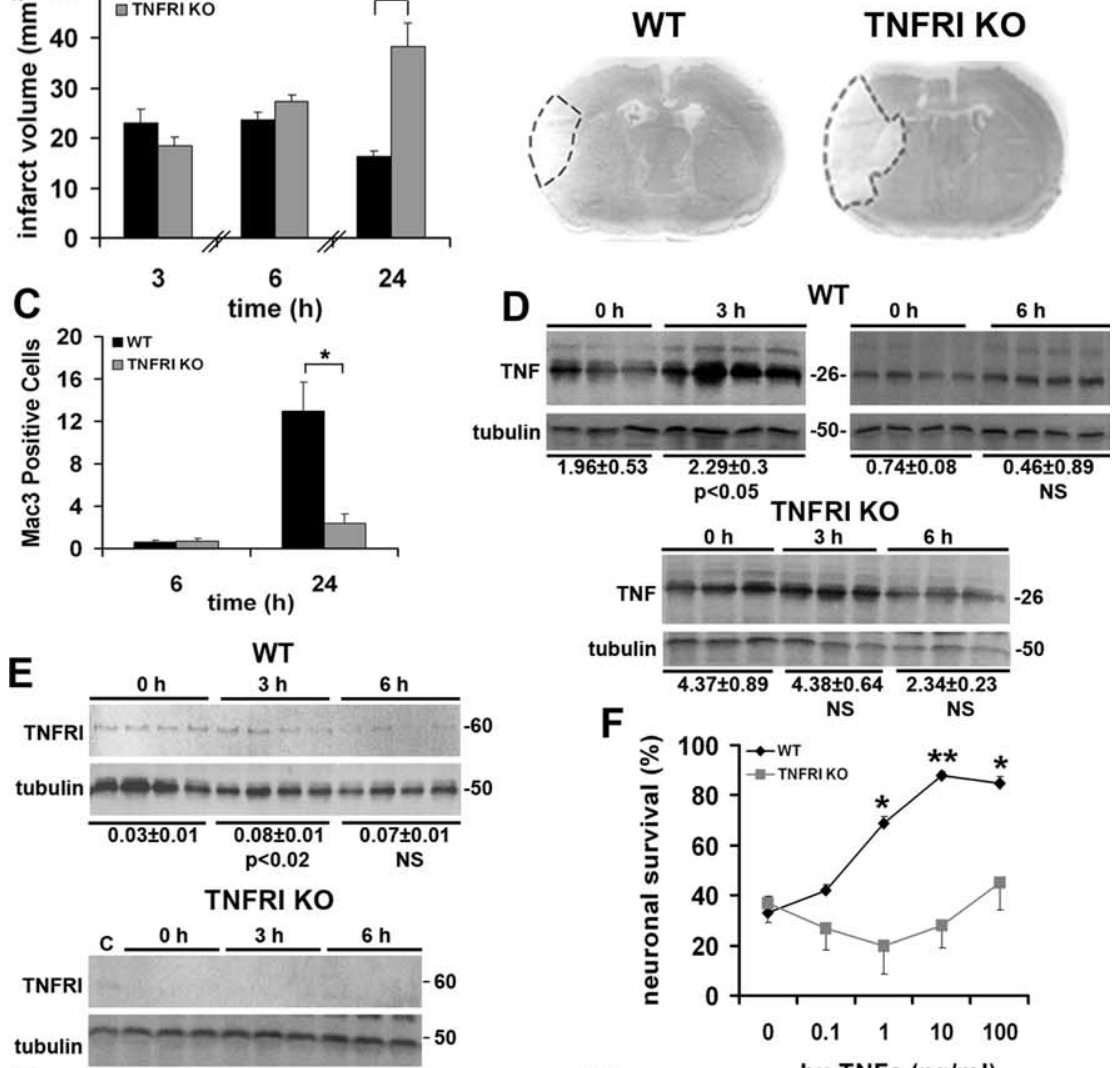

G

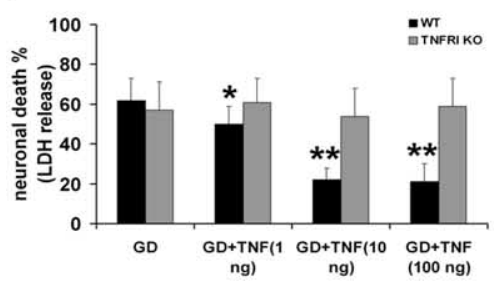

$\mathbf{J}$

I
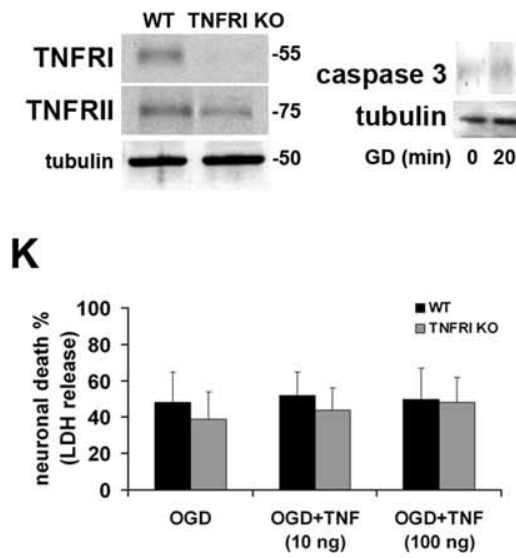

$\mathbf{L}$

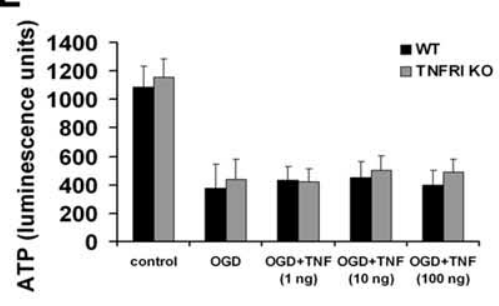

Figure 5. TNFRI mediates neuroprotection in $\mathrm{PMCAO}$ and GD. $A, W T$ and TNFRI KO mice were subjected to $\mathrm{pMCAO}$, and infarct volume was measured, in three independent experiments, at $3 \mathrm{~h}(n=6 \mathrm{WT} ; n=6 \mathrm{TNFRI} \mathrm{KO}), 6 \mathrm{~h}(n=8 \mathrm{WT} ; n=8 \mathrm{TNFRI} \mathrm{KO})$, and $24 \mathrm{~h}\left(n=8 \mathrm{WT} ; n=8\right.$ TNFRI KO). Values represent the mean \pm SEM. ${ }^{*} p<0.001$ for comparison between WT and TNFRI KO mice $24 \mathrm{~h}$ after PMCAO. $\boldsymbol{B}$, Thionin-stained coronal brain sections from WT and TNFRI KO showing the extent of lesion damage $24 \mathrm{~h}$ after pMCAO (outlined). C, Lesion infiltration of WT and TNFRI KO lesions by activated macrophages/microglia $24 \mathrm{~h}$ after pMCAO. Numbers represent the mean number of cells from at least six independent fields per sample. ${ }^{*} p<0.001$ for comparison of Mac3-positive cells in $24 \mathrm{~h}$ WT and TNFRI KO lesions. D, Transmembrane TNF expression levels in WT ( $0 \mathrm{~h}, n=4 ; 3 \mathrm{~h}, n=4 ; 6 \mathrm{~h}$, $n=4)$ and TNFRI KO ( $0 \mathrm{~h}, n=3 ; 3 \mathrm{~h}, n=3 ; 6 \mathrm{~h}, n=3)$ lesions after pMCAO. Values represent the mean densitometry \pm SEM and morphology (Fig. 6C,D). Double immunocytochemistry for NF- $\kappa \mathrm{B}$ p65 and the neuronal marker NeuN confirmed the neuronal identity of p65-immunoreactive cells (Fig. 6D). NF- $\kappa \mathrm{B}$ p65-immunoreactive cells were significantly reduced in ischemic lesions from TNFRI KO mice (Fig. 6E). Collectively, these experiments show that TNFRI is necessary for sustaining neuronal NF- $\kappa \mathrm{B}$ expression and activity after pMCAO.

To investigate the contribution of neurons to TNF/TNFRI-mediated NF- $\kappa \mathrm{B}$ activation after ischemic injury, we performed EMSA in WT and TNFRI KO neurons before and after GD, in the presence or absence of TNF (Fig. 6F). Both WT and TNFRI KO neurons showed constitutive p50/p50- and p50/p65-binding activities, and these were increased $6 \mathrm{~h}$ after GD. Neuronal p50/p50-binding activity was maintained, but p50/p65 activity was selectively depleted, $24 \mathrm{~h}$ after GD. Pretreatment with TNF prevented the depletion of p50/p65 activity in WT, but not TNFRI KO, neurons $24 \mathrm{~h}$ after GD (Fig. $6 F)$. Furthermore, blockade of caspase

significance. NS, Nonsignificant. $\boldsymbol{E}$, TNFRI expression was assessed in PMCAO lesions of WT mice ( $0 \mathrm{~h}, n=4 ; 3 \mathrm{~h}, n=4$; $6 h, n=4)$. To confirm the specificity of the TNFRI antibody, immunoblotting was also performed in TNFRI KO lesions $(0 \mathrm{~h}$, $n=3 ; 3 \mathrm{~h}, n=3 ; 6 \mathrm{~h}, n=3)$, and a WT control was included in the first lane as a positive control. Values represent the mean densitometry \pm SEM and significance. NS, Nonsignificant. $F$, Viability of WT and TNFRI KO neurons pretreated with TNF were measured $24 \mathrm{~h}$ after GD. Neuronal survival values represent the mean survival \pm SEM of triplicates from two independent experiments. ${ }^{*} p<0.05$ for 1 and $100 \mathrm{ng} / \mathrm{ml}$; ${ }^{*} p<0.001$ for $10 \mathrm{ng} / \mathrm{ml}$ TNF-treated neurons compared with untreated cells. hu, Human. $\mathbf{G}$, Neuronal damage quantified by measuring $L D H$ release into the culture medium of WT and TNFRI KO neurons pretreated with different concentrations of TNF $24 \mathrm{~h}$ after GD. ${ }^{*} p<0.05$ and ${ }^{* *} p<0.001$ for comparison of untreated and TNF-treated WT neurons. Results shown represent the mean LDH release \pm SEM of triplicate samples from two independent experiments. $\boldsymbol{H}$, ATP levels of WT and TNFRI KO neurons pretreated with increasing concentrations of TNF, $4 \mathrm{~h}$ after GD. ${ }^{*} p<0.001$ for comparison of untreated and TNF-treated WT neurons. Results shown represent the mean ATP levels \pm SEM of triplicate samples from two independent experiments. $I$, TNFRI and TNFRII expression levels of untreated WT and TNFRI KO neurons. $J$, Caspase 3(p20) expression of untreated and TNF-pretreated WT neurons after GD. For all in vitro experiments, representative results from three independent experiments are shown. $\boldsymbol{K}$, Measurement of LDH release into the culture medium of WT and TNFRI KO neurons pretreated with different concentrations of TNF $24 \mathrm{~h}$ after OGD. Results shown represent the mean $L D H$ release \pm SEM of triplicate samples from two independent experiments. L, ATP levels of WT and TNFRI KO neurons pretreated with increasing concentrations of TNF, $4 \mathrm{~h}$ after OGD. Results represent the mean ATP levels \pm SEM of triplicate samples from two independent experiments. 

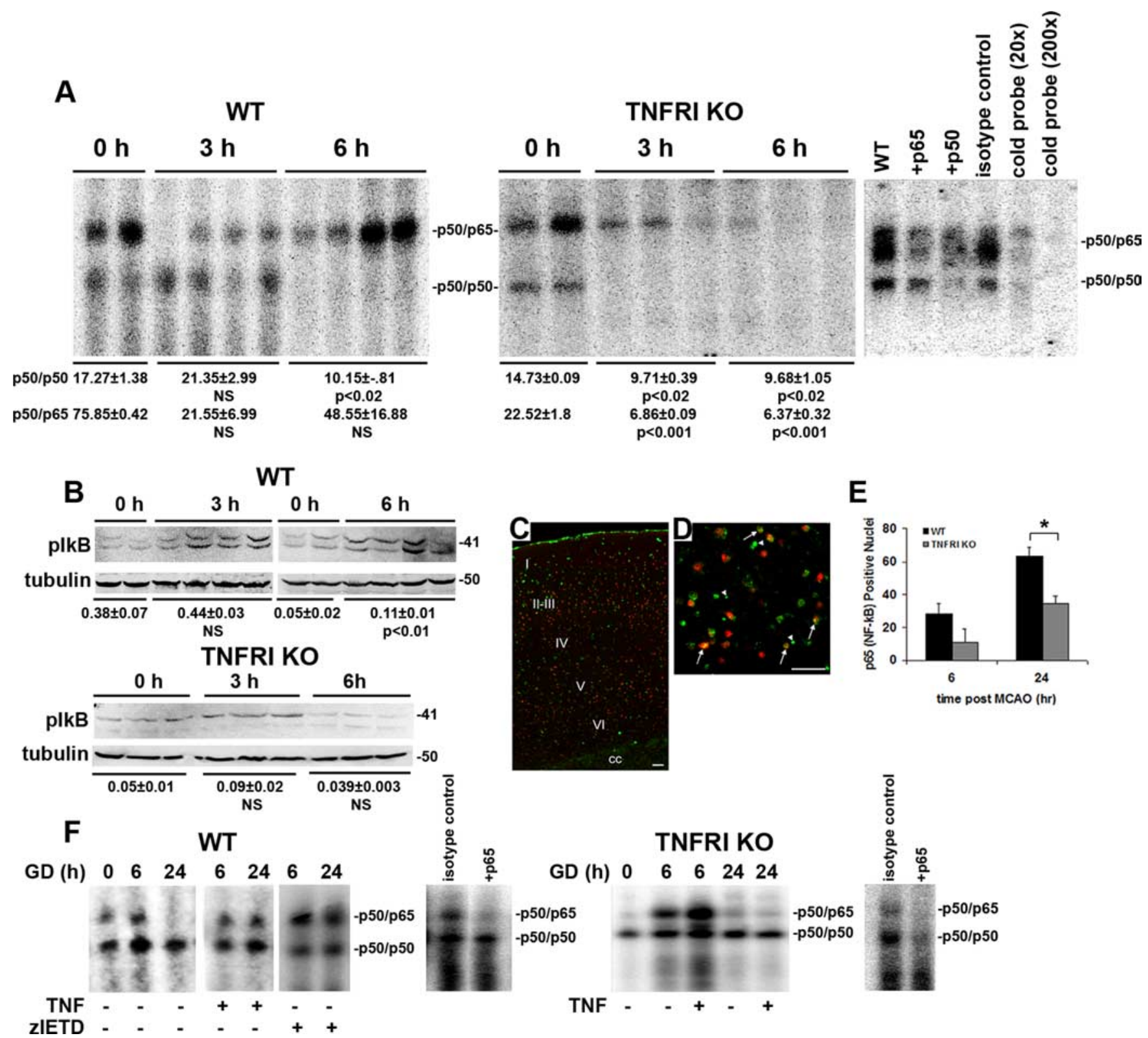

E

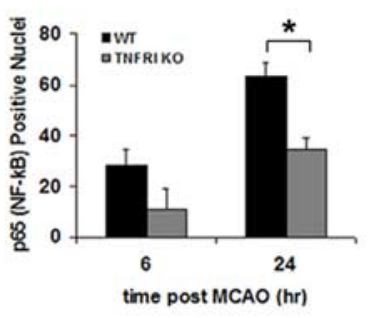

Figure 6. TNFRl is necessary for sustaining NF- $\kappa$ B activity in pMCAO lesions and GD-treated neurons. $A, p 50 / p 50$ and $p 50 / p 65 \kappa B$ binding activity was assessed by EMSA in total extracts from WT $(0 \mathrm{~h}, n=2 ; 3 \mathrm{~h}, n=4 ; 6 \mathrm{~h}, n=4)$ and TNFRI KO $(0 \mathrm{~h}, n=2 ; 3 \mathrm{~h}, n=3 ; 6 \mathrm{~h}, n=3)$ mice after pMCAO. Values represent the mean densitometry \pm SEM and significance. NS, Nonsignificant. Specificity of binding is demonstrated in selected WT extracts (a representative from WT nonoccluded cortex is shown) using an unlabeled oligonucleotide (cold probe) at two different concentrations compared with the labeled probe $(20 \times$ and $200 \times$ ). The specificity of the complexes was further demonstrated using an unlabeled mutant oligo probe (supplemental Fig. 2, available at www.jneurosci.org as supplemental material). Composition analysis of the two NF- $\kappa \mathrm{B}$ complexes was performed using a p50 or a p65 antibody for supershift experiments and an isotype control antibody (IgG) to test the specificity of these antibodies. $B$, I $\kappa B$ phosphorylation was determined in WT ( $\mathrm{h}, n=4 ; 3 \mathrm{~h}, n=4 ; 6 \mathrm{~h}, n=4)$ and TNFRI KO $(0 \mathrm{~h}, n=3 ; 3 \mathrm{~h}, n=3 ; 6 \mathrm{~h}, n=3)$ mice after pMCA0. Values represent the mean densitometry \pm SEM and significance. NS, Nonsignificant. C, $\boldsymbol{D}$, Double-immunofluorescence staining of WT pMCA0 lesions $24 \mathrm{~h}$ after ischemia demonstrates neuron-specific NF- $\kappa B$ p65 activity throughout the cortex $(\boldsymbol{C})$ and neuronal nuclear translocation of p65 (white arrows showing NeuN/red and p65 NF- $\kappa$ B/green-positive cells; $\boldsymbol{D}$ ). Scale bars: C, $240 \mu \mathrm{m} ; \boldsymbol{D}, 75 \mu \mathrm{m}$. E, p65 NF- $\kappa$ B-positive nuclei in WT $(n=4)$ and TNFRI KO $(n=3)$ ischemic lesions at 6 and $24 \mathrm{~h}$ after pMCA0. ${ }^{*} p<0.05$ for comparisons between WT and TNFRI K0 p65-positive nuclei $24 \mathrm{~h}$ after pMCA0. $F$, EMSA was performed in WT and TNFRI KO neurons in the presence or absence of TNF and zIETD-FMK after GD. Representative results from two independent experiments are shown. For supershift experiments, WT and TNFRI KO extracts were preincubated with p65 or an isotype control antibody (IgG)

8-mediated apoptosis in WT neurons by zIETD-FMK also prevented the depletion of p50/p65 activity $24 \mathrm{~h}$ after GD (Fig. 6 F). Our data clearly demonstrate that TNFRI is necessary for the selective maintenance of neuronal p50/p 65 NF- $\kappa$ B activity during the injury response.

TNFRI signaling can also activate JNK, p38MAPK, MAPK, and Akt (Wajant et al., 2003). We assessed the levels of the phosphorylated forms of p38MAPK, SAPK/JNK, MAPK/ERK, and Akt in extracts from WT and TNFRI KO mice taken 3 and $6 \mathrm{~h}$ after pMCAO. Expression patterns were similar in both strains of mice, and no obvious alterations were observed after ischemia (supplemental Fig. 2, available at www.jneurosci.org as supplemental material).

TNFRI is necessary for the upregulation of neuronal FLIP $\mathrm{L}_{\mathrm{L}}$ and FLIP(p43) after GD

To investigate the mechanism by which TNF/TNFRI signaling suppresses GD-induced neuron death, we analyzed the expres- 

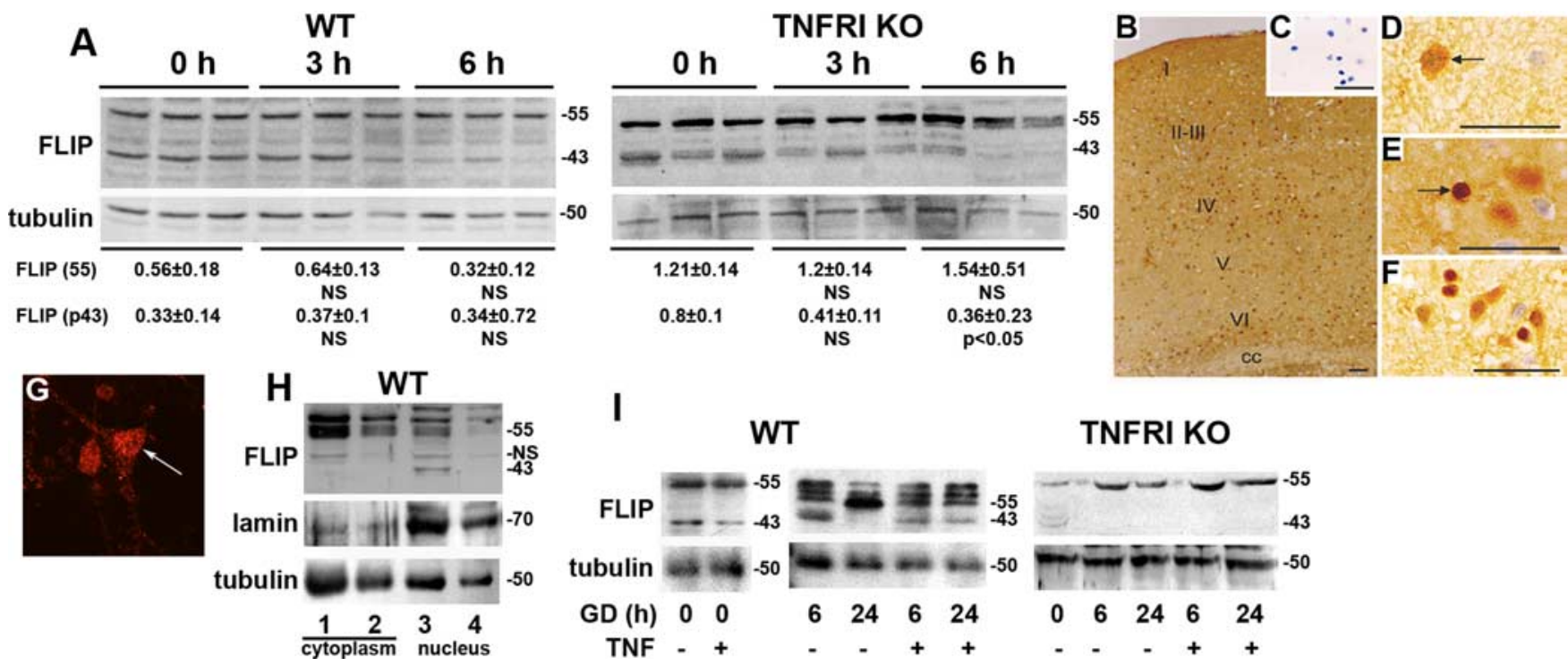

I

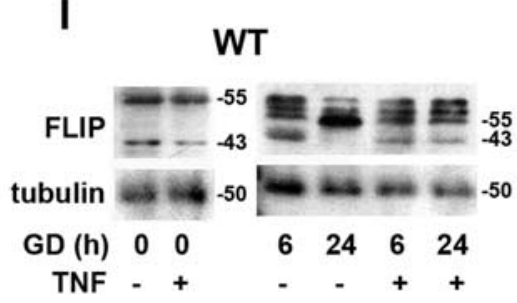

TNFRI KO

Figure 7. FLIP is selectively expressed by neurons, and cleavage to FLIP(p43) is TNF responsive and TNFRI dependent. $A$, WT $(0 \mathrm{~h}, n=3 ; 3 \mathrm{~h}, n=3 ; 6 \mathrm{~h}, n=3)$ and TNFRI KO (0 h, $n=3 ; 3 \mathrm{~h}$, $n=3 ; 6 \mathrm{~h}, n=3$ ) cortical extracts were used to examine the expression level of FLIP, and FLIP(p43) after pMCAO. Values represent the mean densitometry \pm SEM and significance. NS, Nonsignificant. $\boldsymbol{B}-\boldsymbol{F}$, Immunocytochemical analysis of sections from WT ischemic lesions $6 \mathrm{~h}$ after pMCAO reveals FLIP localization in neurons throughout the cortex $(\boldsymbol{B})$ in cells that have neuronal morphology ( $\boldsymbol{C}$; Hoechst staining showing neuronal nuclei). FLIP is localized both in the cytoplasm ( $\boldsymbol{D}$, arrow) and nucleus ( $\boldsymbol{E}$, arrow) of neurons after pMCA0 (D-F).Scale bars: $\boldsymbol{B}, 30 \mu \mathrm{m} ; \boldsymbol{C}, 30 \mu \mathrm{m}$; $D-F, 75 \mu \mathrm{m} . \mathbf{G}$, In addition, FLIP was localized in the nucleus of WT cultured neurons (white arrow). Specificity of the FLIP antibody was demonstrated in preabsorption experiments with rhFLIP protein (supplemental Fig. 3, available at www.jneurosci.org as supplemental material). $\boldsymbol{H}$, The nuclear localization of FLIP and FLIP(p43) was confirmed by Western blot analysis of WT cytoplasmic and neuronal extracts (lane 1,30 $\mu \mathrm{g}$ of cytoplasmic extract; lane 2, $10 \mu \mathrm{g}$ of cytoplasmic extract; lane 3,30 $\mu \mathrm{g}$ of nuclear extract; lane 4, $10 \mu \mathrm{g}$ of nuclear extract). Representative results from two independent experiments are shown. NS, Nonspecific band of $\sim 48 \mathrm{kDa}$. $I$, Protein extracts from WT and TNFRI KO neurons were used to assess FLIP, and FLIP(p43) after GD. Neurons were untreated or pretreated with TNF (100 ng) for $24 \mathrm{~h}$ before the onset of GD. Representative data from two independent experiments are shown.

sion of several proteins involved in apoptosis, including the cellular caspase 8 inhibitory protein FLIP. From the proteins studied, the expression of $\mathrm{Bcl}-2, \mathrm{Bcl}-\mathrm{X}_{\mathrm{L}}, \mathrm{Bad}$, and Bax was detectable at similar levels in WT and TNFRI KO pMCAO lesions (supplemental Fig. 3, available at www.jneurosci.org as supplemental material). However, differences in the expression of FLIP proteins were detected between the two strains. Both $\operatorname{FLIP}_{\mathrm{L}}(55 \mathrm{kDa})$ and FLIP(p43), but not FLIP $(26 \mathrm{kDa})$, were constitutively expressed in WT and TNFRI KO cortex (Fig. 7A) and at higher levels in KO brain. In WT mice, the expression levels of FLIP $_{\mathrm{L}}$ and FLIP(p43) were maintained at 3 and $6 \mathrm{~h}$ after ischemia. In contrast, in TNFRI KO mice, the levels of FLIP $_{\mathrm{L}}$ remained unchanged, but levels of FLIP(p43) were significantly reduced at $6 \mathrm{~h}$ (Fig. 7A). Immunocytochemical localization of FLIP in WT and TNFRI KO brain slices showed expression mainly in cells with neuronal morphology throughout the cerebral cortex (Fig. $7 B, C)$. Interestingly, both cytoplasmic and nuclear localization of FLIP were observed in pMCAO lesions (Fig. $7 D-F$ ) and in primary cortical neurons (Fig. 7G). This localization was further confirmed in cytoplasmic and nuclear extracts from WT neurons in which a preferential localization of $\mathrm{FLIP}_{\mathrm{L}}$ in the cytoplasm and FLIP(p43) in the nucleus was observed (Fig. $7 H$ ). The specificity of the FLIP antibody was determined in preabsorption experiments in which immunostaining by the primary antibody was quenched with increasing concentrations of human recombinant FLIP protein (supplemental Fig. 4, available at www.jneurosci.org as supplemental material).

Consistent with the data from pMCAO lesions, isolated WT and TNFRI KO neurons constitutively expressed FLIP $_{\mathrm{L}}$ and FLIP(p43), but levels were lower in TNFRI KO neurons (Fig. 7I). In WT neurons, both forms could also be detected $6 \mathrm{~h}$ after GD, and posttranslational modifications of $\operatorname{FLIP}_{\mathrm{L}}$ were observed. However by $24 \mathrm{~h}$, where significant cell death was measured, there was selective depletion of FLIP(p43). TNF pretreatment of WT neurons sustained the presence of FLIP(p43) at this time point (Fig. 7I). In sharp contrast, in TNFRI KO neurons, although levels of FLIP $_{L}$ were increased after GD, it was neither cleaved nor modified, even in the presence of TNF (Fig. 7I). These data show that TNFRI is essential for $\mathrm{FLIP}_{\mathrm{L}}$ expression, modification, and cleavage in neurons after GD and that this process cannot be compensated by other DRs.

\section{Neuronal knock-down of FLIP prevents TNF/TNFRI neuroprotection after GD}

To assess the functional contribution of FLIP $_{\mathrm{L}}$ to TNF neuroprotection, we knocked down endogenous FLIP $_{\mathrm{L}}$ expression in neurons by infecting them with an shFLIP-lentiviral vector (pLenti/ shFLIP). Neurons infected for $48 \mathrm{~h}$ expressed markedly reduced levels of FLIP $_{\mathrm{L}}$ and FLIP(p43) (Fig. 8A). Knock-down of FLIP in WT neurons did not significantly alter their sensitivity to GD death but prevented TNF-mediated neuroprotection as shown by Hoechst staining (Fig. $8 \mathrm{~B}$ ) and LDH release (Fig. 8C), demonstrating that FLIP is essential for the TNF/TNFRI neuroprotective signaling mechanism after GD.

\section{Neuronal overexpression of FLIP $_{\mathrm{L}}$ is protective after GD and PMCAO}

To determine whether $\operatorname{FLIP}_{\mathrm{L}}$ can function as a neuroprotective protein after ischemic injury, we infected WT and TNFRI KO neurons with a Semliki Forest virus engineered to express FLIP $_{\mathrm{L}}$ (pSFV-FLIP ${ }_{\mathrm{L}}$-IRESeGFP) and subjected them to GD. pSFVFLIP-IRESeGFP infection of WT neurons resulted in a fivefold increase in the level of $\mathrm{FLIP}_{\mathrm{L}}$ by $12 \mathrm{~h}$ after infection, compared with noninfection or pSFV-IRESeGFP infection controls (Fig. $9 A$ ). pSFV-FLIP ${ }_{\mathrm{L}}$-IRESeGFP potently protected neurons from both strains at $24 \mathrm{~h}$ after GD compared with overexpression of 

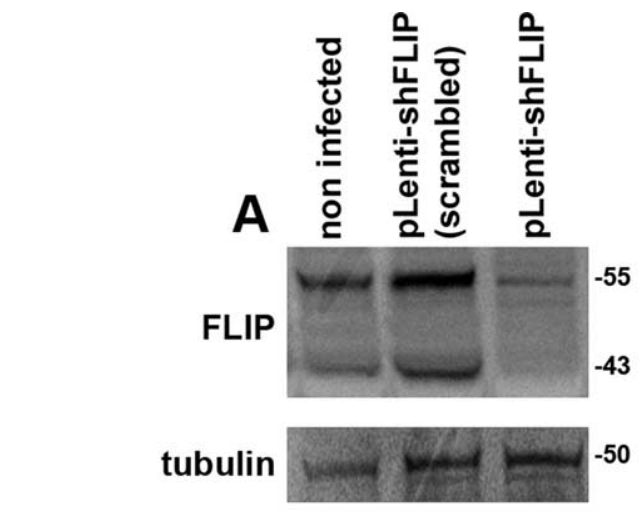

B
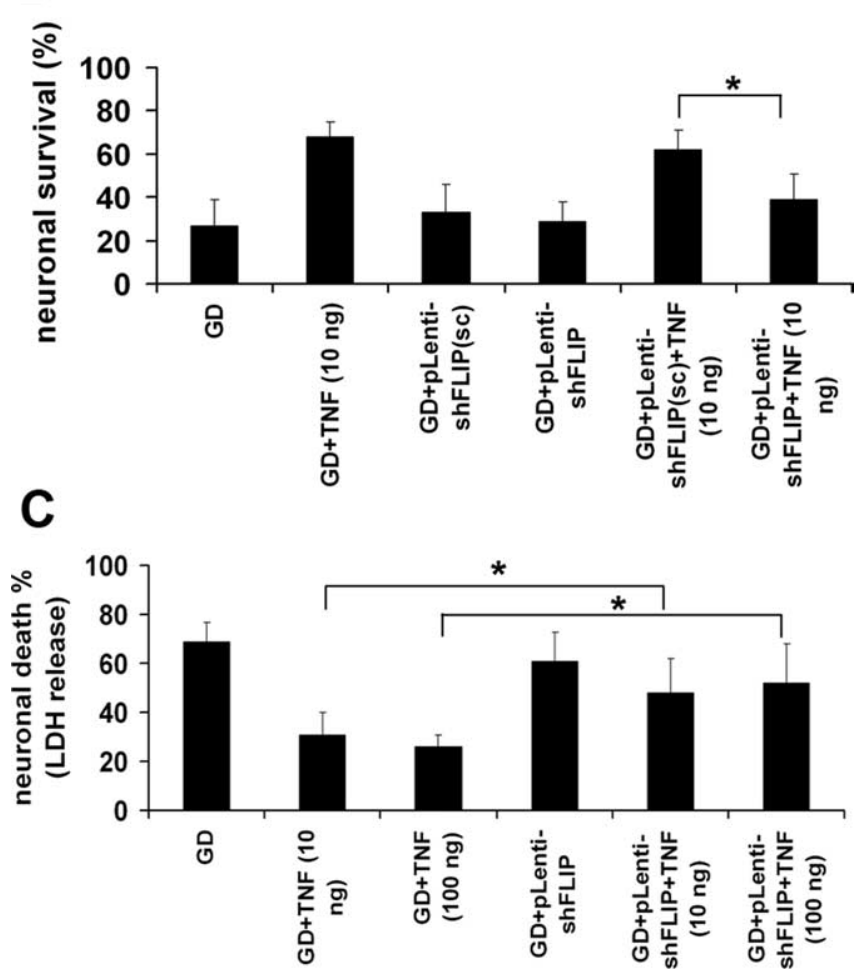

Figure 8. FLIP knock-down in WT neurons prevents TNF-mediated protection. $\boldsymbol{A}$, Western blot analysis of pLenti-shFLIP(scrambled)- and pLenti-shFLIP-infected WT neurons showing efficient and specific reduction of FLIP ${ }_{L}$ and FLIP(p43) expression $48 \mathrm{~h}$ after infection. $\boldsymbol{B}$, Neuronal viability was determined using Hoechst staining of WT neurons, infected either with pLentishFLIP(scrambled) or pLenti-shFLIP and pretreated with TNF $24 \mathrm{~h}$ after GD. ${ }^{*} p<0.05$ for comparison between TNF-treated pLenti-shFLIP(sc) or pLenti-shFLIPWT neurons $24 \mathrm{~h}$ after GD. Results are representative of three experiments performed. sc, Scrambled.C, Measurement of LDH release into the culture medium of pLenti-shFLIP(scrambled) and pLenti-shFLIP WT neurons pretreated with different concentrations of TNF $24 \mathrm{~h}$ after GD. ${ }^{*} p<0.01$. Results shown represent the mean $\mathrm{LDH}$ release \pm SEM of triplicate samples from three independent experiments.

eGFP alone (Fig. 9B). Neurons that were infected with pSFVFLIP-IRESeGFP maintained their normal appearance with smooth soma and outgrown neurites (Fig. 9C, right), in contrast to control pSFV-IRESeGFP-infected neurons, which exhibited swelling and condensation of the soma and neurite fragmentation (Fig. 9C, left). These results show that $\mathrm{FLIP}_{\mathrm{L}}$ overexpression is sufficient to protect neurons in the absence of neuronal TNFRI signaling and further enhances TNFRI-mediated protection in WT neurons, after ischemic injury.

Finally, to determine whether the TNF/TNFRI-FLIP ${ }_{L}$ path- way in neurons contributes to protection after ischemia in vivo, we generated transgenic mice that overexpress FLIP $_{L}$ specifically in neurons under the control of the neurofilament $\mathrm{L}$ promoter $\left(\right.$ TgNFL-FLIP $\left._{\mathrm{L}}\right)$. Transgene expression, measured by reverse transcription (RT)-PCR for the marker protein GFP, was detected specifically in the CNS (both brain and spinal cord) and not other tissues (Fig. 9D), and this was further confirmed by Western blot analysis of GFP and FLIP proteins (Fig. 9E). TgNFL-FLIP $_{\mathrm{L}}$ mice $(n=10)$ subjected to pMCAO for $24 \mathrm{~h}$ had significantly smaller infarcts than littermate controls $(n=9)$ (WT, 26.8 $\pm 5 \mathrm{~mm}^{3}$; TgNFL-FLIP ${ }_{\mathrm{L}}, 18.8 \pm 4 \mathrm{~mm}^{3}$ ) (Fig. $\left.9 F, G\right)$.

\section{Discussion}

Members of the DR family such as Fas and TRAIL receptor 2 are expressed by CNS neurons, during development, in which they are thought to be involved in the deletion of surplus neurons and tissue modeling (Raoul et al., 2000), and in adult, in which they have been associated mainly with neurological dysfunction and neuron loss under pathological situations (Martin-Villalba et al., 1999; Demjen et al., 2004; Aktas et al., 2005). A role for Fas in neurite outgrowth and nerve regeneration in the peripheral nervous system has also been described (Desbarats et al., 2003). Caspase 8, an apical caspase in DR signaling, has been localized in cortical neurons (Velier et al., 1999), and caspase 8 activity was detected in brain after pMCAO (Benchoua et al., 2001). The finding that intracerebroventricular administration of zIETD-FMK limits the development of lesions in a newborn rat hypoxia-ischemia model (Feng et al., 2003) gave the first evidence for a functional role of caspase 8 in ischemia, but there is no data concerning its contribution to the death of neurons. In the present study, we demonstrate that caspase 8 and caspase 3 are activated in CNS after pMCAO and in WT and TNFRI KO cortical neurons subjected to OGD and GD. We also show that caspase 8 activity is necessary for neuronal death after GD. The selective inhibition of active caspase 8 formation by zIETD-FMK peptide, a dominantnegative caspase 8 mutant, or $\mathrm{FLIP}_{\mathrm{L}}$ was sufficient to protect both WT and TNFRI KO neurons against GD-mediated cell death. It is important to note that zIETD-FMK peptide was unable to inhibit OGD-induced cell death, indicating that the mechanism of neuron death is likely to be different between OGD and GD. Because OGD is considered to closely model in vivo ischemia, whereas GD is a model for hypoglycemia, and because cells like astrocytes might provide glucose to neurons in an in vivo setting, the precise contribution of caspase 8 to neuron death in vivo will remain to be determined by the use, for example, of mice in which caspase 8 has been selectively targeted in neurons.

The proinflammatory cytokine TNF and its two receptors, TNFRI and TNFRII, are constitutively expressed by CNS neurons and are inducibly expressed by non-neuronal cells in the brain, such as astrocytes, microglia, and perivascular cells, after injury (Botchkina et al., 1997; Hallenbeck, 2002). However, the function of the TNF ligand/receptor system in the CNS remains controversial, because both neuroprotective and neurotoxic effects have been described. Intracerebroventricular administration of TNF exacerbated focal ischemic injury in hypertensive rats, apparently through an indirect mechanism involving non-neuronal cells (Barone et al., 1997), and antibodies to TNF and TNFbinding proteins have demonstrated cytoprotection in various preclinical ischemia models (Dawson et al., 1996; Barone et al., 1997). A role for TNF in the progression of brain damage is further supported by the finding that lesions in TNF KO mice were reduced in an ischemia-reperfusion model (Martin-Villalba et al., 2001). In general, the deleterious effects of TNF in CNS 
injury can be associated with its activating effects on glia and its procoagulative effects on the vascular system rather than direct neurotoxicity (Barone et al., 1997; Hallenbeck, 2002). In fact, other studies have clearly demonstrated that TNF exerts a potent and direct neuroprotective effect that is associated with maintenance of calcium homeostasis (Cheng et al., 1994; Bruce et al., 1996) and decrease of glutamate-induced currents (Furukawa and Mattson, 1998). In genetic studies, mice deficient in the two TNFRs (Bruce et al., 1996) or TNFRI (Gary et al., 1998) showed exacerbation of neuronal damage after transient MCAO or excitotoxic injury, whereas mice deficient in TNFRII showed increased retinal damage after retinal ischemia-reperfusion (Fontaine et al., 2002; Marchetti et al., 2004). Furthermore, TNF was found to play a beneficial role in ischemic tolerance (Nawashiro et al., 1997) and in lesion repair after traumatic brain injury (Scherbel et al., 1999). However, the cellular and molecular mechanisms underlying such neuroprotective effects of the TNF ligand/receptor system in the CNS are only now beginning to be defined.

In this study, we demonstrate that in pMCAO, as in a transient model of ischemia (Gary et al., 1998), TNFRI is critical for limiting infarct progression and is also necessary for long-term survival of animals. It is possible that the significantly enlarged lesions that are typical of TNFRI $\mathrm{KO}$ mice, which extend into the subcortical and striatal regions of the brain, were responsible for the enhanced mortality in these animals. Furthermore, we show that TNFRI localized on cortical neurons directly protects them from caspase 8 -dependent death induced by GD. To understand how this receptor exerts neuroprotection, we investigated its major downstream signaling pathways. TNF is known to activate JNK, p38MAPK, Akt, and NF- $\kappa$ B signaling pathways (Wajant et al., 2003). Both JNK and $\mathrm{p} 38 \mathrm{MAPK}$ signaling components are expressed in the nervous system under physiological and pathological conditions, in which they have been described to have both protective and damaging effects (Herdegen and Waetzig, 2001). In our system, neither the Akt nor JNK or other MAPK pathways were altered by the absence of TNFRI after cerebral ischemia or in neurons after GD (data not shown). However, TNFRI signaling was found to selectively activate and maintain neuronal activity of the antiapoptotic transcription factor NF- $\kappa \mathrm{B}$ after neuronal injury. In addition to its role in promoting inflammation, one of the primary functions of TNFRI-mediated NF- $\kappa$ B activation is cytoprotection through the induced expression of anti-apoptotic proteins (Karin and Lin, 2002). Constitutive high activity of NF- $\kappa$ B in the brain has been associated with electrical activity within neurons and with synaptic signaling and plasticity (Mattson and
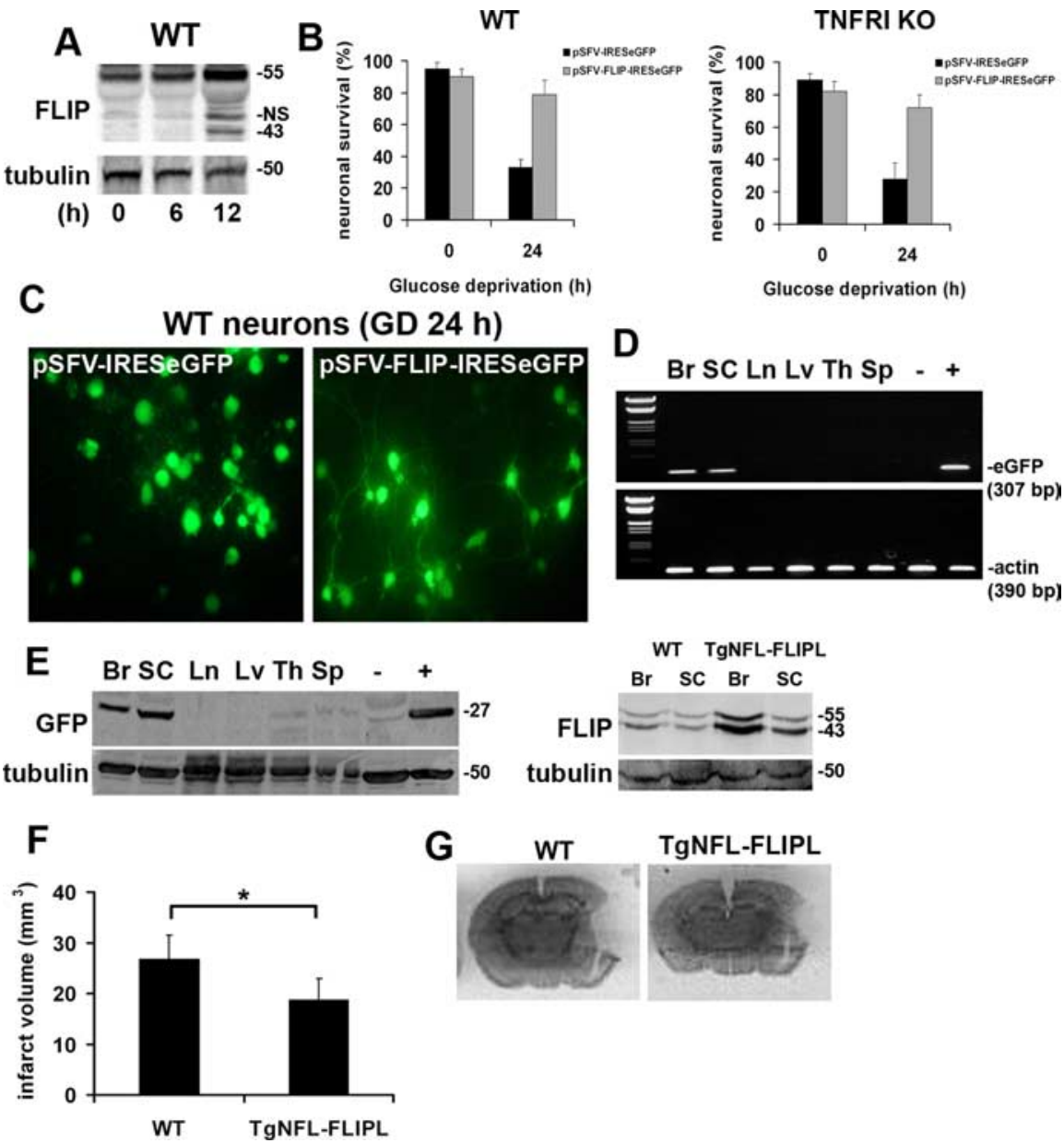

Figure 9. FLIP $P_{L}$ overexpression confers neuroprotection in WT and TNFRI KO neurons after GD and in TgNFL-FLIP mice after a assessed $24 \mathrm{~h}$ after $G D$. Values represent the mean survival \pm SEM of triplicates from two independent experiments. ${ }^{*} p<$ 作 expression in the brain (Br), spinal cord (SC), lymph nodes (Ln), liver (Lv), thymus (Th), and spleen (Sp) of TgNFL-FLIP, mice. A representative sample is shown. Brain CDNA from WT and GFP transgenic mice, were used as negative $(-)$ and positive $(+)$ controls, respectively. $\beta$-Actin was amplified as a loading control. $\boldsymbol{E}$, Left, GFP protein expression level in various tissues, confirming brain- and spinal cord-specific expression of the transgene. Right, FLIP protein expression in the brain and spinal cord of infarct volume was measured after $24 \mathrm{~h}(n=9 \mathrm{WT} ; n=10 \mathrm{TgNFL}-\mathrm{FLIP})$. Values represent the mean $\pm \mathrm{SEM}$. ${ }^{*} p<0.001 . \mathbf{G}$ Thionin staining of WT and TgNFL-FLIP sections showing the extent of infarct $24 \mathrm{~h}$ after PMCAO.

\section{Camandola, 2001; Meffert et al., 2003). Blockade of endogenous}

$\mathrm{NF}-\kappa \mathrm{B}$ activity in cortical neurons through overexpression of an $\mathrm{I} \kappa \mathrm{B}$ super-repressor induced neuronal death (Bhakar et al., 2002 ), and forebrain-specific inhibition of NF- $\kappa$ B potentiated kainate-induced neurotoxicity (Fridmacher et al., 2003).

Here, we extend available knowledge by showing that TNFRI is essential for sustaining high levels of p50/p65 NF- $\kappa$ B activity in lesions after pMCAO and in isolated cortical neurons after GD. Furthermore, comparison of the expression of several NF- $\kappa \mathrm{B}$ target proteins involved in apoptosis between TNFRI KO and WT samples revealed a role for TNFRI in the selective upregulation of $\mathrm{FLIP}_{\mathrm{L}}$ and its $\mathrm{p} 43$ DISC-associated cleavage form $[$ FLIP $(\mathrm{p} 43)]$ in cortical neurons after GD and in pMCAO lesions. In contrast, an effect of TNFRI on the expression of other apoptosis proteins studied ( $\mathrm{Bcl}-2, \mathrm{Bcl}-\mathrm{X}_{\mathrm{L}}, \mathrm{Bad}$, and $\mathrm{Bax}$ ) in $\mathrm{pMCAO}$ lesions was not detected. Following our observation that caspase 
8 is activated in cortical neurons after GD and OGD and is critical for GD-induced neuronal death, independently of the presence of TNFRI, and given that both $\operatorname{FLIP}_{\mathrm{L}}$ and $\mathrm{FLIP}(\mathrm{p} 43)$ are selective inhibitors of caspase 8 activation (Krueger et al., 2001), we hypothesized that one mechanism of TNFRI-mediated neuroprotection after ischemic injury is through neuronal NF- $\kappa \mathrm{B}$ activation and $\mathrm{FLIP}_{\mathrm{L}}$ induction. Indeed, the knock-down of endogenous FLIP in WT neurons made them resistant to TNF protective effects. Also by overexpressing FLIP $_{\mathrm{L}}$ in neurons of WT and TNFRI KO mice with a viral vector and neurons of transgenic mice, we now show a novel and direct role for $\operatorname{FLIP}_{\mathrm{L}}$ in neuroprotection after GD and pMCAO, respectively. Thus, FLIP $_{\mathrm{L}}$ overexpression enhanced the protection of GD-treated WT neurons, was sufficient to reconstitute neuroprotection in TNFRI KO GD-treated neurons, and significantly limited pMCAO lesion development in TgNFL-FLIP ${ }_{\mathrm{L}}$ transgenic mice. Because FLIP $_{\mathrm{L}}$ and FLIP(p43) block caspase 8 apoptosis by preventing additional caspase 8 recruitment to the DISC and can also induce NF- $\kappa$ B activation (Tschopp et al., 1998; Peter and Krammer, 2003; Kataoka and Tschopp, 2004), it is possible that FLIP $_{\mathrm{L}}$ can act in a positive-feedback survival loop whereby caspasedependent processing of $\operatorname{FLIP}_{\mathrm{L}}$ to $\mathrm{FLIP}(\mathrm{p} 43)$ further enhances NF- $\kappa$ B activation and FLIP $\mathrm{L}_{\mathrm{L}}$ production. Also, sustained TNFRI$\mathrm{NF} \kappa \mathrm{B}$ signaling might be able to maintain high levels of neuronal FLIP $_{\mathrm{L}}$ expression by protecting it from JNK-mediated ubiquitination and proteasome degradation (Chang et al., 2006). Our results do not exclude the possibility that non-neuronal cells of the CNS or additional TNFRI targets such as Mn-SOD (manganese superoxide dismutase) (Bruce et al., 1996), calbindin- $D_{28 \mathrm{k}}$ (Cheng et al., 1994), Bcl-2 and Bcl-X (Tamatani et al., 1999), and NF- $\kappa \mathrm{B}$-induced survival factors such as erythropoietin (Figueroa et al., 2002) also contribute to TNFRI-mediated neuroprotection.

The present findings give significant insight into an essential role for TNF/TNFRI signaling in CNS neuroprotection, revealing a major physiological function of this cytokine in tissue protection after injury that is independent of its proinflammatory effects and providing a possible explanation for the failure of clinical trials using systemic TNF blocking agents in multiple sclerosis patients (The Lenercept Multiple Sclerosis Study Group and The University of British Columbia MS/MRI Analysis Group, 1999). Our results indicate that targeting of neuronal TNFRI signaling pathways may represent a valuable approach for enhancing neuron survival after CNS injury.

\section{References}

Aktas O, Smorodchenko A, Brocke S, Infante-Duarte C, Topphoff US, Vogt J, Prozorovski T, Meier S, Osmanova V, Pohl E, Bechmann I, Nitsch R, Zipp F (2005) Neuronal damage in autoimmune neuroinflammation mediated by the death ligand TRAIL. Neuron 46:421-432.

Barger SW, Horster D, Furukawa K, Goodman Y, Krieglstein J, Mattson MP (1995) Tumor necrosis factors alpha and beta protect neurons against amyloid beta-peptide toxicity: evidence for involvement of a kappa B-binding factor and attenuation of peroxide and $\mathrm{Ca} 2+$ accumulation. Proc Natl Acad Sci USA 92:9328-9332.

Barone FC, Arvin B, White RF, Miller A, Webb CL, Willette RN, Lysko PG, Feuerstein GZ (1997) Tumor necrosis factor-alpha. A mediator of focal ischemic brain injury. Stroke 28:1233-1244.

Benchoua A, Guegan C, Couriaud C, Hosseini H, Sampaio N, Morin D, Onteniente B (2001) Specific caspase pathways are activated in the two stages of cerebral infarction. J Neurosci 21:7127-7134.

Bernaudin M, Marti HH, Roussel S, Divoux D, Nouvelot A, MacKenzie ET, Petit E (1999) A potential role for erythropoietin in focal permanent cerebral ischemia in mice. J Cereb Blood Flow Metab 19:643-651.

Bhakar AL, Tannis LL, Zeindler C, Russo MP, Jobin C, Park DS, MacPherson S, Barker PA (2002) Constitutive nuclear factor- $\kappa$ B activity is required for central neuron survival. J Neurosci 22:8466-8475.
Borsello T, Clarke PG, Hirt L, Vercelli A, Repici M, Schorderet DF, Bogousslavsky J, Bonny C (2003) A peptide inhibitor of c-Jun N-terminal kinase protects against excitotoxicity and cerebral ischemia. Nat Med 9:1180-1186.

Botchkina GI, Meistrell III ME, Botchkina IL, Tracey KJ (1997) Expression of TNF and TNF receptors (p55 and p75) in the rat brain after focal cerebral ischemia. Mol Med 3:765-781.

Bruce AJ, Boling W, Kindy MS, Peschon J, Kraemer PJ, Carpenter MK, Holtsberg FW, Mattson MP (1996) Altered neuronal and microglial responses to excitotoxic and ischemic brain injury in mice lacking TNF receptors. Nat Med 2:788-794.

Chang L, Kamata H, Solinas G, Luo JL, Maeda S, Venuprasad K, Liu YC, Karin M (2006) The E3 ubiquitin ligase itch couples JNK activation to TNFalpha-induced cell death by inducing c-FLIP(L) turnover. Cell 124:601-613.

Cheng B, Christakos S, Mattson MP (1994) Tumor necrosis factors protect neurons against metabolic-excitotoxic insults and promote maintenance of calcium homeostasis. Neuron 12:139-153.

Culmsee C, Siewe J, Junker V, Retiounskaia M, Schwarz S, Camandola S, El Metainy S, Behnke H, Mattson MP, Krieglstein J (2003) Reciprocal inhibition of $\mathrm{p} 53$ and nuclear factor- $\kappa \mathrm{B}$ transcriptional activities determines cell survival or death in neurons. J Neurosci 23:8586-8595.

Dawson DA, Martin D, Hallenbeck JM (1996) Inhibition of tumor necrosis factor-alpha reduces focal cerebral ischemic injury in the spontaneously hypertensive rat. Neurosci Lett 218:41-44.

Demjen D, Klussmann S, Kleber S, Zuliani C, Stieltjes B, Metzger C, Hirt UA, Walczak H, Falk W, Essig M, Edler L, Krammer PH, Martin-Villalba A (2004) Neutralization of CD95 ligand promotes regeneration and functional recovery after spinal cord injury. Nat Med 10:389-395.

Deng Y, Ren X, Yang L, Lin Y, Wu X (2003) A JNK-dependent pathway is required for TNFalpha-induced apoptosis. Cell 115:61-70.

Desbarats J, Birge RB, Mimouni-Rongy M, Weinstein DE, Palerme JS, Newell MK (2003) Fas engagement induces neurite growth through ERK activation and p35 upregulation. Nat Cell Biol 5:118-125.

Dirnagl U, Iadecola C, Moskowitz MA (1999) Pathobiology of ischaemic stroke: an integrated view. Trends Neurosci 22:391-397.

Dohrman A, Russell JQ, Cuenin S, Fortner K, Tschopp J, Budd RC (2005) Cellular FLIP long form augments caspase activity and death of $\mathrm{T}$ cells through heterodimerization with and activation of caspase-8. J Immunol 175:311-318.

Feng Y, Fratkin JD, LeBlanc MH (2003) Inhibiting caspase-8 after injury reduces hypoxic-ischemic brain injury in the newborn rat. Eur J Pharmacol 481:169-173.

Figueroa YG, Chan AK, Ibrahim R, Tang Y, Burow ME, Alam J, Scandurro AB, Beckman BS (2002) NF-kappaB plays a key role in hypoxiainducible factor-1-regulated erythropoietin gene expression. Exp Hematol 30:1419-1427.

Fontaine V, Mohand-Said S, Hanoteau N, Fuchs C, Pfizenmaier K, Eisel U (2002) Neurodegenerative and neuroprotective effects of tumor necrosis factor (TNF) in retinal ischemia: opposite roles of TNF receptor 1 and TNF receptor 2. J Neurosci 22: RC216(1-7).

Fridmacher V, Kaltschmidt B, Goudeau B, Ndiaye D, Rossi FM, Pfeiffer J, Kaltschmidt C, Israel A, Memet S (2003) Forebrain-specific neuronal inhibition of nuclear factor- $\kappa \mathrm{B}$ activity leads to loss of neuroprotection. J Neurosci 23:9403-9408.

Furukawa K, Mattson MP (1998) The transcription factor NF-kappaB mediates increases in calcium currents and decreases in NMDA- and AMPA/ kainate-induced currents induced by tumor necrosis factor-alpha in hippocampal neurons. J Neurochem 70:1876-1886.

Gary DS, Bruce-Keller AJ, Kindy MS, Mattson MP (1998) Ischemic and excitotoxic brain injury is enhanced in mice lacking the p55 tumor necrosis factor receptor. J Cereb Blood Flow Metab 18:1283-1287.

Hallenbeck JM (2002) The many faces of tumor necrosis factor in stroke. Nat Med 8:1363-1368.

Herdegen T, Waetzig V (2001) AP-1 proteins in the adult brain: facts and fiction about effectors of neuroprotection and neurodegeneration. Oncogene 20:2424-2437.

Hu WH, Johnson H, Shu HB (2000) Activation of NF-kappaB by FADD, Casper, and caspase-8. J Biol Chem 275:10838-10844.

Ivanov TR, Brown IR (1992) Interaction of multiple nuclear proteins with the promoter region of the mouse $68-\mathrm{kD}$ a neurofilament gene. J Neurosci Res 32:149-158. 
Kaltschmidt B, Uherek M, Wellmann H, Volk B, Kaltschmidt C (1999) Inhibition of NF-kappaB potentiates amyloid beta-mediated neuronal apoptosis. Proc Natl Acad Sci USA 96:9409-9414.

Karin M, Lin A (2002) NF-kappaB at the crossroads of life and death. Nat Immunol 3:221-227.

Kataoka T, Tschopp J (2004) N-terminal fragment of c-FLIP(L) processed by caspase 8 specifically interacts with TRAF2 and induces activation of the NF-kappaB signaling pathway. Mol Cell Biol 24:2627-2636.

Koh JY, Choi DW (1987) Quantitative determination of glutamate mediated cortical neuronal injury in cell culture by lactate dehydrogenase efflux assay. J Neurosci Methods 20:83-90.

Krueger A, Schmitz I, Baumann S, Krammer PH, Kirchhoff S (2001) Cellular FLICE-inhibitory protein splice variants inhibit different steps of caspase-8 activation at the CD95 death-inducing signaling complex. J Biol Chem 276:20633-20640.

Lee JM, Grabb MC, Zipfel GJ, Choi DW (2000) Brain tissue responses to ischemia. J Clin Invest 106:723-731.

Lewis M, Tartaglia LA, Lee A, Bennett GL, Rice GC, Wong GH, Chen EY, Goeddel DV (1991) Cloning and expression of cDNAs for two distinct murine tumor necrosis factor receptors demonstrates one receptor is species specific. Proc Natl Acad Sci USA 88:2830-2834.

Li H, Zhu H, Xu CJ, Yuan J (1998) Cleavage of BID by caspase 8 mediates the mitochondrial damage in the Fas pathway of apoptosis. Cell 94:491-501.

Lundstrom K, Abenavoli A, Malgaroli A, Ehrengruber MU (2003a) Novel Semliki Forest virus vectors with reduced cytotoxicity and temperature sensitivity for long-term enhancement of transgene expression. Mol Ther 7:202-209.

Marchetti L, Klein M, Schlett K, Pfizenmaier K, Eisel UL (2004) Tumor necrosis factor (TNF)-mediated neuroprotection against glutamate-induced excitotoxicity is enhanced by $N$-methyl-D-aspartate receptor activation. Essential role of a TNF receptor 2-mediated phosphatidylinositol 3-kinase-dependent NF-kappa B pathway. J Biol Chem 279:32869-32881.

Martin-Villalba A, Herr I, Jeremias I, Hahne M, Brandt R, Vogel J, Schenkel J, Herdegen T, Debatin KM (1999) CD95 ligand (Fas-L/APO-1L) and tumor necrosis factor-related apoptosis-inducing ligand mediate ischemiainduced apoptosis in neurons. J Neurosci 19:3809-3817.

Martin-Villalba A, Hahne M, Kleber S, Vogel J, Falk W, Schenkel J, Krammer $\mathrm{PH}$ (2001) Therapeutic neutralization of CD95-ligand and TNF attenuates brain damage in stroke. Cell Death Differ 8:679-686.

Martinou JC, Dubois-Dauphin M, Staple JK, Rodriguez I, Frankowski H, Missotten M, Albertini P, Talabot D, Catsicas S, Pietra C (1994) Overexpression of BCL-2 in transgenic mice protects neurons from naturally occurring cell death and experimental ischemia. Neuron 13: 1017-1030.

Mattson MP, Camandola S (2001) NF-kappaB in neuronal plasticity and neurodegenerative disorders. J Clin Invest 107:247-254.

Meffert MK, Chang JM, Wiltgen BJ, Fanselow MS, Baltimore D (2003) NFkappa B functions in synaptic signaling and behavior. Nat Neurosci 6:1072-1078.

Misra RS, Jelley-Gibbs DM, Russell JQ, Huston G, Swain SL, Budd RC (2005) Effector CD4+ T cells generate intermediate caspase activity and cleavage of caspase-8 substrates. J Immunol 174:3999-4009.

Nawashiro H, Tasaki K, Ruetzler CA, Hallenbeck JM (1997) TNF-alpha pretreatment induces protective effects against focal cerebral ischemia in mice. J Cereb Blood Flow Metab 17:483-490.

Nicole O, Ali C, Docagne F, Plawinski L, MacKenzie ET, Vivien D, Buisson A (2001) Neuroprotection mediated by glial cell line-derived neurotrophic factor: involvement of a reduction of NMDA-induced calcium influx by the mitogen-activated protein kinase pathway. J Neurosci 21:3024-3033.
Peter ME, Krammer PH (2003) The CD95(APO-1/Fas) DISC and beyond Cell Death Differ 10:26-35.

Raoul C, Pettmann B, Henderson CE (2000) Active killing of neurons during development and following stress: a role for p75(NTR) and Fas? Curr Opin Neurobiol 10:111-117

Rossler K, Neuchrist C, Kitz K, Scheiner O, Kraft D, Lassmann H (1992) Expression of leucocyte adhesion molecules at the human blood-brain barrier (BBB). J Neurosci Res 31:365-374.

Rothe J, Lesslauer W, Lotscher H, Lang Y, Koebel P, Kontgen F, Althage A Zinkernagel R, Steinmetz M, Bluethmann H (1993) Mice lacking the tumour necrosis factor receptor 1 are resistant to TNF-mediated toxicity but highly susceptible to infection by Listeria monocytogenes. Nature 364:798-802.

Scherbel U, Raghupathi R, Nakamura M, Saatman KE, Trojanowski JQ, Neugebauer E, Marino MW, McIntosh TK (1999) Differential acute and chronic responses of tumor necrosis factor-deficient mice to experimental brain injury. Proc Natl Acad Sci USA 96:8721-8726.

Schneider A, Martin-Villalba A, Weih F, Vogel J, Wirth T, Schwaninger M (1999) NF-kappaB is activated and promotes cell death in focal cerebral ischemia. Nat Med 5:554-559.

Shinoda S, Skradski SL, Araki T, Schindler CK, Meller R, Lan JQ, Taki W, Simon RP, Henshall DC (2003) Formation of a tumour necrosis factor receptor 1 molecular scaffolding complex and activation of apoptosis signal-regulating kinase 1 during seizure-induced neuronal death. Eur J Neurosci 17:2065-2076.

Tamatani M, Che YH, Matsuzaki H, Ogawa S, Okado H, Miyake S, Mizuno T, Tohyama M (1999) Tumor necrosis factor induces Bcl-2 and Bcl-x expression through NFkappaB activation in primary hippocampal neurons. J Biol Chem 274:8531-8538.

The Lenercept Multiple Sclerosis Study Group, The University of British Columbia MS/MRI Analysis Group (1999) TNF neutralization in MS: results of a randomized, placebo-controlled multicenter study. Neurology 53:457-465.

Tschopp J, Irmler M, Thome M (1998) Inhibition of fas death signals by FLIPs. Curr Opin Immunol 10:552-558.

Tu S, McStay GP, Boucher LM, Mak T, Beere HM, Green DR (2006) In situ trapping of activated initiator caspases reveals a role for caspase- 2 in heat shock-induced apoptosis. Nat Cell Biol 8:72-77.

Valable S, Montaner J, Bellail A, Berezowski V, Brillault J, Cecchelli R, Divoux D, MacKenzie ET, Bernaudin M, Roussel S, Petit E (2005) VEGFinduced BBB permeability is associated with an MMP-9 activity increase in cerebral ischemia: both effects decreased by Ang-1. J Cereb Blood Flow Metab 25:1491-1504

Velier JJ, Ellison JA, Kikly KK, Spera PA, Barone FC, Feuerstein GZ (1999) Caspase- 8 and caspase- 3 are expressed by different populations of cortical neurons undergoing delayed cell death after focal stroke in the rat. J Neurosci 19:5932-5941.

Wajant H, Pfizenmaier K, Scheurich P (2003) Tumor necrosis factor signaling. Cell Death Differ 10:45-65.

Welsh FA, Sakamoto T, McKee AE, Sims RE (1987) Effect of lactacidosis on pyridine nucleotide stability during ischemia in mouse brain. J Neurochem 49:846-851.

Zhang WH, Wang X, Narayanan M, Zhang Y, Huo C, Reed JC, Friedlander RM (2003) Fundamental role of the Rip2/caspase-1 pathway in hypoxia and ischemia-induced neuronal cell death. Proc Natl Acad Sci USA 100: 16012-16017. 